\title{
TRABAJO Y DERECHO: UN PADRE AUSENTE, EL CONFLICTO SOCIAL*
}

\author{
ÁlVARo Domínguez MONTOYA** \\ Patricio Mella Cabrera***
}

\begin{abstract}
RESUMEN: La presente investigación se enmarca en un análisis crítico al modelo de relaciones laborales existentes en las sociedades que se adscriben a una economía de mercado, aludiéndose a los fundamentos ideológicos de la regulación del trabajo en tal escenario. En este contexto, el estudio aborda las funciones del Derecho del Trabajo y la construcción de las relaciones de poder/contrapoder en las relaciones laborales, destacando la importancia de la centralidad o no centralidad del trabajo en una sociedad democrática. Finalmente se realizan reflexiones sobre el rol modelador del Derecho del Trabajo en nuestro país.
\end{abstract}

PALABRAS CLAVE: Derecho y conflicto social - Derecho del Trabajo funciones del Derecho del Trabajo

\section{WORK AND LAW: AN ABSENT FATHER, THE SOCIAL CONFLICT}

\begin{abstract}
This research is part of a critical analysis of the labor relations model existent in societies that are assigned to market economies, referring to the ideological foundations of labor regulations of such model. In this context, this study addresses the functions of labor law and the construction of relations of power and counter power in labor relations, emphasizing the importance of the centrality of labor or the lack of it, in
\end{abstract}

Este trabajo forma parte de la investigación realizada en el contexto del proyecto "Curso de Derecho del trabajo" N ${ }^{\circ} 12.051 .003-10$, patrocinado por la Dirección de Investigación de la Universidad de Concepción, Chile.

Fecha de recepción: 26 de mayo de 2014.

Fecha de aceptación: 26 de agosto de 2014.

* Abogado. Licenciado en Ciencias Jurídicas y Sociales, Universidad de Concepción (Chile). Estudiante en Máster en Drets Sociolaborals [2014-2015], Universitat Autónoma de Barcelona (España). Correo electrónico: aedodominguez@gmail.com

*** Abogado. Licenciado en Ciencias Jurídicas y Sociales; Magíster en Derecho, Universidad de Concepción (Chile). Profesor asociado, Departamento de Derecho Laboral, Universidad de Concepción (CHILE). Correo electrónico: patmella@udec.cl 
a democratic society. Finally, reflections on the modeler role of labor law in our country are made.

KEY WORDS: Law and social conflict - Labor Law - functions of Labor Law

Sumario: Notas Preliminares; 1) El Trabajo. Algunas aproximaciones teóricas, (1.1) La concepción del trabajo en la Teoria Critica; (1.2) El trabajo en un modelo de mercado. Liberalismo y Neoliberalismo; (1.3) El estado actual del Trabajo. Posmodernidad y crisis; 2) Derecho del Trabajo Moderno: contextualización y claves para su entendimiento; (2.1) El derecho, el Derecho del Trabajo y algunas aproximaciones criticas para su comprensión; (2.3) Las funciones del Derecho del Trabajo: la Protección y la Pacificación Social; 3) La contribución de la Organización Sindical en la regulación del Conflicto; Observaciones Finales; Bibliografía.

\section{Notas PRELIMinares}

En general podemos afirmar que históricamente nuestras sociedades son sociedades fundadas en el trabajo humano, constituyendo el eje central sobre el cual discurre el Derecho del Trabajo en cuanto fenómeno normativo. Sin embargo, ante tal cuestión elemental, los esfuerzos teóricos y prácticos se han enfocado en estudiar y comprender su finalidad desde el surgimiento de normas protectoras normalmente de rango legal que buscan igualar el desequilibrio que se produce entre el que presta los servicios y quien los utiliza, abordando el Derecho del Trabajo como un fenómeno puramente adjetivo mediante el análisis preferente de las fuentes escritas institucionales, ajeno a los conflictos y realidad social que tales temas engloban ${ }^{1}$, lo que determina que los planteamientos teóricojurídicos tradicionales aborden de manera marginal el rol del derecho y su relación con lo sociolaboral, siendo "el enemigo número uno del Derecho del Trabajo la abstracción o el esquematismo"2, particularmente en la medida que este derecho, desde el contrato y la totalidad de las otras fuentes

1 Diría Javillier, Jean-Claude: "las reglas del Derecho del Trabajo no se pueden aislar de su contexto: el jurista debe dar prueba de gran humildad", todo lo anterior a propósito del "Método de análisis" y la autorreferencia epistemológica del derecho, afirmando en páginas posteriores que "ninguna disciplina concreta es capaz, pese a su entidad, de captar todos los aspectos del análisis social, es porque la naturaleza del análisis social requiere de un método de síntesis". Javillier, Jean-Claude (1982) Derecho del Trabajo. Madrid: Ed. Instituto de Estudios Laborales y Seguridad Social, 640 pp., p. 28 y ss.

2 Camerlynk, G.H.; Lyon- Caen, G. (1974) Derecho del Trabajo. Madrid: Ed. Aguilar, 545 pp., p. 5. 
laborales, norman al mismo tiempo la reproducción del hombre ante la realidad. De allí arranca la imperiosa necesidad de reincorporar una comprensión crítica de lo jurídico que nos permita replantear el Derecho del Trabajo, particularmente si nos situamos en el contexto en que se desenvuelve.

\section{1) El Trabajo. Algunas aproximaciones teóricas}

1.- En el modelo de sociedad actual se produce un arduo debate respecto del trabajo humano, su rol y centralidad ${ }^{3}$, su relación con la organización de los medios de producción y los cambios que se producen en la estructura social como reflejo de la adopción de políticas de empleo y su impacto en el derecho, sin muchas veces evaluar su sentido e importancia en determinados contextos sociales.

Lo anterior tiene profundas implicancias en la vida social e individual de todo ser humano, por cuanto el trabajo en una primera aproximación conlleva dos elementos básicos: la decisión de realizar una labor, esto es, el carácter voluntario de la actividad laboral que se pretende desarrollar, en principio con cualquier finalidad, sea esta para asegurar su sobrevivencia, sea por solidaridad, colaboración o incluso recreación, descartando la imposición de una labor y; un segundo aspecto, el de carácter relacional del trabajo, en virtud del cual el sujeto realiza una labor a fin de cumplir un mandato social de trabajar como una exigencia impuesta por la comunidad, fundado en el carácter gregario del individuo y la inevitable colaboración mutua que requiere para enfrentar tanto la sobrevivencia propia como la de su familia.

En este contexto cada persona se ve obligada a enfrentar una realidad propia, ejecutando un juicio de valor de las responsabilidades que debe

3 La distinción entre la centralidad o no centralidad del Trabajo recae en la discusión de si el trabajo además de posibilitar la supervivencia, otorgar un significado a la vida y si mediante el mismo se pueden analizar otras dimensiones que posibilitan la integración y participación de la sociedad, esto es si el trabajo posee la función de proporcionar o determinar una identidad personal y social a los individuos. (Esteban Aguillo, Tomás (1998). "La centralidad del trabajo en el proceso de construcción de la identidad de los jóvenes". Revista Psicothema, vol. 10, No 1, pp. 153-165). En un aspecto general, la centralidad debe entenderse como la creencia acerca del valor de trabajar en la vida de las personas, distinguiendo dos componentes principales: el de creencia/valor que implica una orientación valorativa sobre el trabajar como un rol en la vida, identificable con la creencia resultante de un proceso cognitivo basado en la comparación entre el trabajo como actividad y las percepciones del "yo". El resultado de esta comparación es el desarrollo de un tipo de identificación con el trabajo que puede ser central o periférica según la importancia del mismo para el propio sujeto. Un segundo aspecto como componente valorativo/afectivo, incluye la involucración con el trabajo y el compromiso con el mismo como respuesta afectiva de la vida personal. PÉrEz GonzÁlez, José; Díaz Vilela, Luis (2005) La centralidad del trabajo. USA: LULU, 168 pp. 
asumir, teniendo en cuenta su capacidad, como así también los objetivos concretos y específicos que pretende cumplir. Aun más, cada persona en el acto de trabajo "debe enfrentar el grado de equilibrio entre las fuerzas de la vida y las fuerzas de la muerte en su propio ser" ${ }^{4}$ por lo que el "trabajo" como idea no puede ser concebido como un mecanismo para satisfacer necesidades exclusivamente materiales, ya que desde él pende una tensión permanente de correspondencia entre la percepción de realidad tanto externa como interna, lo que conlleva la evaluación de cada sujeto frente a la sociedad.

2.- En este esquema, la idea que se tiene del Trabajo es central en la discusión, pero no en los términos reduccionistas como generalmente se propone -valorización y desprecio del trabajo ${ }^{5}$ o aún más, desde el productivismo o antiproductivismo- ${ }^{6}$ sino desde el concepto amplio y acotado del mismo ${ }^{7}$. Estos últimos abordan, de manera antagónica, la naturaleza autotélica ${ }^{8}$ del trabajo, esto es si tiene el trabajo en sí su propio fin, y a su vez, la centralidad o no centralidad del mismo ${ }^{9}$ como fenómeno social y cultural. En otros términos la pregunta es hasta qué punto el trabajo constituye el pilar sobre el cual descansan las bases de funcionamiento de la sociedad.

Por lo mismo el análisis conceptual del Trabajo recibe las influencias de distintas tesis político-filosóficas que pretenden explicar su papel y que confluyen en los diferentes modelos normativos del mismo ${ }^{10}$. Sobre

JaQues, Elliott (1968) Trabajo, incentivos y redistribución. Buenos Aires: Editorial Hormé S.A.E., Paidós, 373 pp., p. 29.

5 Noguera, José Antonio (2002). "El concepto de trabajo y la teoría social crítica". Revista de Sociología Universidad Autónoma de Barcelona, Papers No 68, 141-168 pp., p. 144.

6 Noguera (2002) 146 y ss.

7 Noguera, José Antonio (1998) La transformación del concepto de trabajo en la teoría social: La aportación de las tradiciones marxistas, tesis doctoral. Barcelona: Universidad Autónoma de Barcelona, 316 pp., p. 102-207.

8 La etimología griega de esta dicción indica que se compone de autos, por sí, y telos, fin, aplicándose para designar toda acción que lleva en sí misma la justificación de su propio fin.

9 Noguera (2002) 147 y ss.

10 Sobre este punto hacemos referencias a las obras ya citadas agregando: Godio, Julio (2011) Sociología del trabajo y politica. Buenos Aires: Editorial Corregidor, 252 pp.; SANCHIs, Enric (2011) Trabajo y paro en la sociedad postindustrial. Valencia: Editorial Tirant lo Blanch, 335 pp. Desde un punto de vista Jurídico laboralista, sobre el régimen jurídico del trabajo a través de la historia, apreciaciones filosóficas y jurídicas: Cabanellas de Torres, Guillermo (1987) Compendio de Derecho Laboral. Tomo I, vol. 13º Ed. Buenos Aires: Editorail Helisiasta, pp. 79-114; Borrajo Dacruz, Efrén (1989) Introducción al Derecho del Trabajo, $6^{\circ}$ Ed. Madrid: Editorial TECNOS. 324 pp., p 21-30; 44-50.; Agregamos Lagos Matus, Gustavo (1950) El problema histórico del Trabajo. Santiago: Editorial Jurídica, 258 p.; Montoya Melgar, Alfredo (1995) Derecho del Trabajo. 16a. Ed. Madrid: Editorial TECNOS, 802 pp., pp. 49-76. Desde las influencias ideológicas y como estas influyen en el Derecho del Trabajo: Barbagelata, Héctor-Hugo (2009) Curso sobre la evolución del pensamiento Juslaboralista. Montevideo: FCU, 337 pp.; Romagnoli, Umberto (1997) El Derecho, el Trabajo y la historia. Madrid: Consejo Económico y Social. 224 pp.; Palomeque, Manuel (2002) Derecho del Trabajo e ideología. Madrid: Editorial TECNOS, 177 pp. 
el punto creemos útil realizar algunas apreciaciones orientadoras de la complejidad de estas, como así también sus divergencias, ya que desde el punto de vista sociológico e histórico la conceptualización del Trabajo ha ido variando en su valoración por parte de las diversas culturas, como así también variaron las formas sociales que este ha ido adquiriendo ${ }^{11}$, cuestión que necesariamente es tomada en cuenta al momento de crear las normas jurídicas que regularán la actuación de los individuos en una época determinada, particularmente dentro de la interacción entre el capital y el trabajo en la sociedad actual.

3.- Dicho lo anterior, para efectos ilustrativos, señalaremos aquellos autores y teorías que a nuestro criterio dan cuenta de explicaciones generales de qué es el Trabajo y las variaciones de su apreciación en el tiempo, con la observación que se descarta un análisis pormenorizado de sus aspectos históricos y sociológicos por una cuestión de extensión, no obstante ser conscientes de la importancia de estos estudios en nuestra área ${ }^{12}$.

\section{1) LA CONCEPCión DEL TRABajo EN la TeORÍA CRÍTICA ${ }^{13}$}

1.- Los planteamientos desarrollados por la Teoría Crítica en el ámbito del trabajo, como fenómeno social, se inspiran "en valores emancipatorios al servicio de una transformación social que aumente los grados de autonomía y autorrealización de los individuos; más concretamente, se

11 Bencomo, Tania (2008). "El trabajo visto desde una perspectiva social y jurídica”. Revista Latinoamericana de Derecho Social, No 7, julio-diciembre, pp. 27-57. JAVILLIER (1982) 28-41.

En general se suele asociar la teoría crítica con los planteamientos desarrollados por la Frankfurter Schule (Escuela de Frankfurt), no obstante que la primera es mucho más amplia que la segunda. Los miembros de la Escuela de Frankfurt se encontraban inmersos en la tradición de la teoría marxista, enfocándose en desarrollar sus planteamientos en oposición a la teoría tradicional partiendo de la base que tanto los objetos observados como los sujetos observadores de la ciencia están constituidos socialmente y, por lo tanto, deben ser analizados dentro de su contexto histórico-social, definiendo su estudio a partir de una filosofía materialista de la historia como marco de referencia para sus interpretaciones. Para la materia que nos importa, la Teoría Crítica no ofrece una teoría del Derecho unificada -más aún cuando sus fronteras se expandieron a otras latitudes distinta a la alemana- sin embargo, sus líneas interpretativas se encuentran unidas bajo la columna vertebral de identificar las deficiencias y contradicciones de la descripción positivista de la "realidad" del Derecho. Como principales autores de esta línea encontramos a Horkheimer, Marcuse, Adorno, Neumann y Kirchheimer. Para una aproximación en sus diversas variantes de la teoría crítica en el Derecho recomendamos de manera introductoria Pérez Lledó, Juan (2005) "Teorías críticas del Derecho", en Ernesto Garzón Valdés y Francisco Laporta (editores), El derecho y la justicia, Editorial Trotta.; Wolkmer, Antonio Carlos (2006) Introducción al pensamiento jurídico crítico. D.F: ILSA/UASLP/CEDH, 163 pp.; Correas, Óscar (1998) Sociología del Derecho y Critica Juridica. D.F: Editorial Fontamara, 224 pp.; Atienza, Manuel y Ruiz Manero, Juan (2004) Marxismo y Filosofía del Derecho. D.F: Editorial Fontamara, 194 pp.; Воввіо, Norberto, (2001) Ni con Marx ni contra Marx. D.F: Editorial FCE, 283 p.; Miaille, Michel, Jeammaud, Antoine et al. (2008) La Crítica Jurídica en Francia. Puebla: 
trata de la tradición que ha renunciado a cualquier tipo de esencialismo ahistórico que decida de antemano sobre «la naturaleza» de un fenómeno como el trabajo humano" 14 . Esta postura desarrolla sus argumentaciones siguiendo parcialmente a MARX, en función de su conocida interpretación materialista de la historia y particularmente su tesis del plusvalor ${ }^{15}$.

Para estas apreciaciones en la que confluyen implicancias cognitivas instrumentales, esto es una búsqueda constante de un fin, compuesto por diversos factores como la producción o creación de valores de uso; aspectos prácticos-morales con alcance social-moral (como construcción y medio de solidaridad, creador de vínculos incardinados en un sentido comunicativo); y aspectos ético-expresivos, abarcando la autoexpresión y autorrealización personal como sujeto individual y colectivo ${ }^{16}$, muy a diferencia de un concepto reducido que solo enfoca el trabajo en aspectos productivistas, como acción instrumental, deber social o disciplina coercitiva.

2.- Para esta tesis, las directrices planteadas son identificables en el trabajo como la relación directa y activa del hombre con su entorno, con la naturaleza, siendo expresión de las facultades con la que se desarrolla como individuo y especie ${ }^{17}$, abriéndose espacio para la expresividad de la esencia humana en que la racionalidad se determina por la autocreación de lo humano en el trabajo. En esta óptica se puede sostener que el trabajo humano no es otra cosa que la reproducción del hombre en la realidad en donde plasma su fin: "al final del proceso de trabajo brota un resultado

Universidad Autónoma de Puebla; Correas, Óscar (2005), Critica de la ideología jurídica. D.F.: UNAM, 258 p.; Cerroni, Umberto (1965), Marx y el Derecho Moderno. Buenos Aires: Editorial Jorge Âlvarez Editor, 237 pp.; Pérez Llego, Juan (1993) El Movimiento Critical Legal Studies, tesis doctoral, Alicante: Universidad de Alicante, Facultad de Derecho, 817 pp. Disponible en: http://rua.ua.es/dspace/handle/10045/3825 [fecha de visita 30 de enero de 2014]. Sobre el punto que se desarrolla en este acápite, se siguen los postulados desarrollados particularmente en las investigaciones realizadas por Noguera, José Antonio, sobre el trabajo y su relación con la teoría social crítica en su desarrollo, explicación y crítica. Sobre el punto ver Noguera (1998); (2000). "El problema de la definición del trabajo", Ponencia presentada en los I Encuentros entre Humanidades y Ciencias Sociales, Institut Universitari de Cultura, Universitat Pompeu Fabra, Inédito, fecha 18-20 de enero de 2000, Barcelona: inédita. p. 42. Disponible en: https://www.academia.edu/attachments/5743527/ download_file [fecha de visita 30 de enero de 2014] y (2002).

14 Noguera (2000) 142 y 143.

15 Plusvalor o plusvalía es la expresión monetaria del valor que el trabajador asalariado crea por encima del valor de su fuerza de trabajo y que se apropia el capitalista. Este concepto y definición fue desarrollado por Karl Marx a partir de la crítica a los economistas clásicos precedentes que ya la habían enunciado aunque de manera incompleta como Adam Smith y David Ricardo. Ver Marx, Karl (1966) El Capital: Critica de la Economía Politica, Tomo I. DF: FCU. 953 pp., pp. 130-444; (1999), Capital, Trabajo, Plusvalia: Conceptos Básicos. Buenos Aires: Errepal, 159 pp.

16 Noguera (1998) 26-98.

17 Fromm, Erich (1962) Marx y su Concepto del Hombre. D.F: Editorial Fondo de Cultura Económica. 272 pp., pp. 58 y ss. 
que antes de comenzar aquel existía ya en la mente del obrero, es decir, un resultado que tenía existencia ideal. El obrero no se limita a hacer cambiar de forma la materia que le brinda la naturaleza, sino que, realiza en ella su fin, fin que él sabe que rige como una ley las modalidades de su actuación y al que tiene necesariamente que supeditar su voluntad"18.

El trabajo humano es fundamental en los procesos de autorrealización, en la medida que el esfuerzo y dolor son actos de superación que se conjeturan en la autodeterminación del potencial humano y sus capacidades sociales, suponiendo una actividad y esfuerzo libre en la conducción del mismo, mediante la elección consciente de actividades para desarrollarse, reproducirse y desenvolverse como ser social. Según Supiot, curiosamente la palabra trabajo designa el sufrimiento que ha de soportar la mujer en el parto, el acto en el cual se mezcla el dolor y la creación, que se concreta en el misterio de la condición humana: "al traer hijos y producir obras, el hombre cumple su destino" 19 , siendo la forma de praxis en la que "el hombre llega verdaderamente a serlo, se crea a sí mismo, en la lucha con la naturaleza, sometiéndola a su voluntad, humanizándola; de que, mediante el trabajo, el hombre, al desprenderse de su animalidad, toma conciencia de su existencia, de su especificidad, de su libertad" ${ }^{20}$.

Esta percepción no es un resumen de características bien intencionadas y de difícil justificación. Al contrario, ella se valida con las permanentes y cada vez más masivas demandas sociales que reclaman un mejor trato a los asalariados, incluso no como un grupo excluido, sino al revés, empoderado y consciente que su escasa participación en los beneficios que genera el desarrollo económico, no tiene justificación técnica y moral. Esta postura debilita la concepción tradicional de la relación de trabajo, basada en el predominio del dueño de los medios de producción y que encuentra su reconocimiento en la subordinación del asalariado a dicho capital. En nuestra opinión, al menos en modelos como el nuestro, se advierte un progresivo reconocimiento a la igualdad de trato que debe recibir quien presta sus servicios en forma subordinada, recibiendo el impacto de la teoría de los derechos fundamentales laborales que postula una primacía constitucional en el diseño de la relación de trabajo, vinculándose al trabajo decente ${ }^{21}$, que sitúan la dignidad del trabajador como eje central.

\footnotetext{
18 Marx, (1966) 130 y 131.

19 Supiot, Alain (1996) Critica del Derecho del Trabajo. Madrid: Ministerio del Trabajo y Asuntos Sociales, 312 pp. p. 20.

20 Camerlynk, G.H, Lyon- Caen, G. (1974) 3.

21 Como señaló ERmida, “Trátese de un "slogan”, de un concepto integrado, de un objetivo para la acción, o de todas esas cosas a la vez, la noción de trabajo decente contiene dos énfasis importantes: en primer lugar denota una clara preocupación ética y en segundo lugar una preocupación por la calidad del empleo. Ninguna de ambas connotaciones es menor. La preocupación ética por el tipo de trabajo remite a las mejores tradiciones del Derecho del
} 
3.- Esta línea teórica permite, sobre la base del trabajo emancipado o libre, la edificación y construcción de modelos económicos y políticos con proyecciones sociales de cohesión, unidas por la búsqueda común de mejores condiciones de vida y existencia, tanto para el sujeto individual como colectivo, mediante apoyo y servicios recíprocos, siendo valores centrales la autonomía y solidaridad que se entrelazan y completan. En este tipo de trabajo -que idealmente debería conducir a una sociedad emancipada- ${ }^{22}$, descansa la idea y posibilidad de incorporar la más amplia diversidad de ocupaciones según el deseo y el placer de cada uno, de modo que se convierta en una respuesta que se vuelve autoexpresión, realización de sí para sí y para los demás. No obstante, en estos términos, el trabajo es, empíricamente, la precondición material de la existencia humana, pero no esencial al hombre, ya que como tal se define por su sociabilidad: el hombre es, cuando es social.

La producción no se plantea como un fin en sí misma, sino lo contrario, sus términos son prioritarios para el desarrollo humano, de tal modo que el hombre domine la producción y no al contrario: la acumulación del goce y no el goce de la acumulación, la riqueza no como consumo o acumulación, sino como tiempo libre y autorrealización. Esto nos permite visualizar un concepto de trabajo que reintegra y emancipa, desde una centralidad societal y consecuencialmente en una economía de trabajo emancipado.

4.- Realizadas las disquisiciones anteriores, estimamos que todo esto no puede comprenderse plenamente sin entender la noción de trabajo que rige actualmente nuestra sociedad: el trabajo enajenado.

trabajo y de la OIT, según ya se ha visto. La preocupación por la calidad del empleo supone un viraje notable luego de 20 o 30 años de preocupación, si no exclusiva, sí hegemónica por la cantidad del empleo. En efecto, agobiados por la penuria del empleo, la OIT, muchos gobiernos y otros actores que inciden en el mundo del trabajo, llegaron a justificar cualquier tipo de creación de puestos de trabajo, con tal que los mismos disminuyeran alguna décima la tasa de desempleo y aun cuando se tratara de lo que en la Argentina se calificaron como "empleos basura" o "empleos chatarra". La emergencia del concepto de trabajo decente supone una reacción frente a esa situación: por supuesto que es necesario crear empleo; por supuesto que es necesario bajar la tasa de desempleo; pero el empleo a crear tiene que ser un empleo mínimamente digno, las condiciones de trabajo deben ser por lo menos decentes."

Es así que se ha definido al trabajo decente como un trabajo productivo, en el cual se respeten los derechos, y en el cual se goce de protección social”. Ermida Uriarte, Óscar (2006). "Ética y Derecho del Trabajo". Iuslabor, No 1, Universitat Pompeu Fabra, disponible en: http://www.upf.edu/iuslabor/_pdf/2006-1/ErmidaUriarteEtica.pdf [fecha de visita 30 de enero de 2014].

Sobre el trabajo decente ver Somavía, Juan (1999). Trabajo decente. Memoria del Director General, 87a Conferencia Internacional del Trabajo. OIT: Ginebra. Disponible en: http:// www.ilo.org/public/spanish/standards/relm/ilc/ilc87/rep-i.htm [fecha de visita 30 de enero de 2014]

22 Ver Amézquita Quintana, Constanza, (2009). “Alienación y Emancipación. Una reflexión teórica sobre estos dos conceptos”. Revista de Ciencias Sociales Comunicación, Cultura y Politica, No 1, vol. 2, pp. 45-54. 
En términos generales la enajenación o extrañamiento ${ }^{23}$, significa que el hombre no se experimenta a sí mismo como factor activo en la captación del mundo, sino que el mundo, la naturaleza, los demás y el mismo, permanecen ajenos a él ${ }^{24}$, cuestión que se expresa en el trabajo y en la división del mismo ${ }^{25}$. El trabajo no es otra cosa que, en los términos ya descritos, la relación activa del hombre con la naturaleza, la creación de un mundo nuevo, incluyendo la creación de un hombre nuevo, pero en la medida que la propiedad, la división del trabajo y sus productos se cosifican y mercantilizan, el trabajo como tal pierde su carácter autorrealizador, asumiendo una existencia separada del hombre, ajena de sí. Luego "el objeto producido por el trabajo, su producto, se opone ahora a él como un ser ajeno, como un poder independiente del productor. El producto del trabajo es trabajo encarnado en un objeto y convertido en cosa física; este producto es una objetivación del trabajo. La realización del trabajo es, al mismo tiempo, su objetivación. La realización del trabajo aparece en la esfera de la economía política como una invalidación del trabajador, la objetivación como una pérdida y como servidumbre al objeto y la apropiación como enajenación" 26 . Esta noción, se encuentra en sintonía con la cosificación del trabajo, es decir una cosa susceptible de apropiación, toda vez que se hace independiente del sujeto que la produce.

El trabajo enajenado, en estos términos, deja de ser de la naturaleza del trabajador, "en consecuencia no se realiza en su trabajo sino que se niega, experimenta una sensación de malestar más que de bienestar, no desarrolla libremente sus energías mentales y físicas sino que se encuentra físicamente exhausto y mentalmente abatido", por lo mismo, "de ahí que el obrero se sienta en su casa fuera del trabajo y en el trabajo fuera de sí. Está en casa cuando no trabaja, y cuando trabaja no está en casa. Su trabajo, por lo tanto, no es voluntario, sino obligado, trabajo forzado. No es, por lo tanto, la satisfacción de una necesidad, sino solo un medio para satisfacer necesidades fuera de este. Su carácter ajeno lo pone de relieve el hecho de que, tan pronto deja de existir alguna coacción física o de cualquier otro tipo, se huye del trabajo como de la peste" ${ }^{27}$ El trabajo se convierte en una necesidad impuesta al hombre desde fuera, para satisfacer

23 La alienación, como categoría no es unívoca por lo que recomendamos para un profundización AmÉzQuita Quintana, Constanza (2009) "Alienación y Emancipación. Una reflexión teórica sobre estos dos conceptos". Revista de Ciencias Sociales Comunicación, Cultura y Política, 1, 2, pp. 45-54.

24 Fromm (1962) 55.

25 Sobre la división del trabajo ver Valverde, Martín et al., Derecho del Trabajo (4a ed.). Madrid: Tecnos. 888 pp., pp. 32 y ss.; Panzieri, Rainero, et al. (1989) La división capitalista del trabajo. Córdoba: Cuadernos de Pasado y Presente, 204 pp.

26 MarX, Karl (1884) Manuscritos económico-filosóficos de 1844, p. 105. Apéndice en Fromm, Erich (1962)

$27 \quad$ Marx (1884) 108. 
necesidades externas y fictas, el trabajo se vuelve "parcelario y dividido, destructor de su libertad. Y entonces la vida no comienza más que con el fin del trabajo, es decir, con el ocio o el descanso" 28 .

5.- Los fundamentos del trabajo para esta postura, se centran en la actividad misma, sin abordar, "el cómo debe proveerse el trabajo", cuestión vital para lograr los fines emancipatorios que proclama, ya que una población numerosa que se disputa puestos de trabajo escasos, llevan inevitablemente a un deterioro de las condiciones de los mismos. En relación con este punto, las alternativas sobre las cuales se han pronunciado las sociedades modernas varían entre dejar exclusivamente al mercado la producción de empleos, o es el Estado quien mediante un proceso de planificación a largo plazo diseña un plan de generación de empleos que dé respuesta oportuna y suficiente a la demanda de trabajo, no existiendo -al menos desde un punto de vista jurídico- proyectos alternativos de producción.

\section{2) EL TRABAJO EN UN MODELO DE MERCADO. LibERALISMO Y NEOLIBERALISMO ${ }^{29}$}

1.- En general y de manera sintética, expondremos algunas de la tesis desarrolladas por diversos autores que son agrupados indistintamente dentro de las teorías liberales y neoliberales. Si bien no puede afirmarse que corresponden a una escuela económica homogénea o derechamente una línea uniforme del pensamiento, sin duda han delineando el modelo capitalista actual al dotarlo de una serie de características que hoy dan forma a lo que conocemos como tal. En este punto se hace necesario examinar la relación entre el trabajo y su valor para tal postura.

Sobre el punto que nos convoca, SMITH afirma que la clave del bienestar social está en el crecimiento económico que se materializa mediante la reorganización de los factores productivos a través de la división y especialización del trabajo, la que se profundiza a medida que se amplía la extensión de los mercados y que permite posibilidades ilimitadas para que la sociedad aumente su riqueza y su bienestar mediante la producción especializada y el comercio entre las naciones. Este autor centra su explicación desde la "paradoja del valor" 30 en el trabajo humano, siendo este el

28 Camerlynk, G.H, Lyon- Caen, G. (1974) 3.

29 Sobre el punto y para un análisis más profundo, recomendamos una detallada investigación enfocada en el ámbito de la economía teórica y el derecho del trabajo desde un enfoque liberal, de la cual obtuvimos referencias bibliográficas y autores citados en este apartado. Al respecto ver: Martínez Rivera, Ramón (2012), Estudios de economía y legislación laboral, memoria de prueba para optar al grado de Licenciado en Ciencias Jurídicas y Sociales, Facultad de Derecho, Universidad de Chile.

30 La paradoja del valor (o paradoja del diamante y el agua) es una paradoja sobre el valor económico que expresa que, aunque el agua es más útil que los diamantes, estos tienen un 
fundamento del valor de cambio de las mercancías ${ }^{31}$, afirmando que las riquezas provienen de este último, siendo el trabajo humano en última instancia la causa de valor, centrando en este su explicación: ¿en el valor de cambio ${ }^{32}$.

Las tesis expuesta por SMITH fueron refutadas por los planteamiento de una predominante corriente económica moderna, en cuanto no coinciden con su explicación de la paradoja del valor ni con la relación existente con los precios y el intercambio, haciendo hincapié en las tesis de uso subjetivo $^{33}$, en la cual el valor de un bien no depende de la propiedad del mismo, sino más bien en la utilidad subjetiva otorgada por las personas, en la cual intervienen sus actitudes y apreciaciones en base a la satisfacción y percepción de sus necesidades ${ }^{34}$.

Tal diferenciación marca un punto de inflexión en la estructuración de las ideas liberales y que permite construir y justificar un modelo de sociedad definido por la división técnica del trabajo basado en la propiedad privada de los medios de producción ${ }^{35} \mathrm{y}$ en las relaciones contractuales de colaboración mutua ${ }^{36}$.

precio más alto en el mercado. Señala SMith graficando tal paradoja: "Nada es más útil que el agua; pero esta no comprará nada; nada de valor puede ser intercambiado por ella. Un diamante, por el contrario, tiene escaso valor de uso; pero una gran cantidad de otros bienes pueden ser frecuentemente intercambiados por este".

31 Sмiтh señala "El precio real de cada cosa, lo que realmente cuesta a quien la adquiere, es el esfuerzo y fatiga que supone su adquisición. Lo que realmente vale para el hombre que la posee y quiere desprenderse de ella o intercambiarla por algo, es el esfuerzo y fatiga que le puede evitar y que puede trasladar a otros individuos. Lo que se compra con dinero o con otros bienes se adquiere con el trabajo, del mismo modo que lo que adquirimos con el esfuerzo de nuestro propio cuerpo. El dinero o esos bienes nos ahorran el esfuerzo. Contiene el valor de una cierta cantidad de trabajo que intercambiamos por las cosas que suponemos contienen una misma cantidad de trabajo. El trabajo fue el primer precio, la moneda originaria que sirvió para pagar todas las cosas. No fue mediante el oro o la plata, sino mediante el trabajo como se compró toda la riqueza del mundo; y su valor, para los que la poseen y quieren intercambiarla por nuevos productos, es exactamente igual a la cantidad de trabajo que se puede adquirir y disponer con aquella." Sмітн, Adam (1988) La riqueza de las naciones. Vol I. Barcelona: Oikos-tau, 585 pp., p. 115.

32 Bencomo (2008) 33, 34.

33 Menger, Carl (1985) Principios de economía politica. Madrid: Unión Editorial, 255 pp., p. 123 y ss; Mises, Ludwig (1986) La acción humana. Tratado de Economía, 4a Edición, Madrid: Unión Editorial, 1302 pp., pp. 154, 157, 196, 498.

34 De forma más general ver: Huerta de Soto, Jesús (2001), Nuevos Estudios de Economía Política. Madrid: Unión Editorial, 493 pp., pp. 27 y ss.; Huerta de Soto, Jesús (2004) Estudios de Económica Política, 2a Edición, Madrid: Unión Editorial, 342 pp., pp. 19 y ss.

35 Mises (1986) 947 y ss.

36 En opinión de Mises, las sociedades se organizan sobre la base de dos diferentes formas de cooperación social: "la cooperación en virtud de contrato y voluntaria coordinación" y "la cooperación en virtud de mando y subordinación, es decir, hegemónica”, la primera exige ciertamente que los contratantes se encuentren en situación igual o similar, lo que descarta la prevalencia de uno y otro. En la segunda, se impone el poder o dirección de uno sobre el otro, el que se subordina al primero, y por ende, el que obedece se transforma en un instrumento del dirigente. Respecto de este ultimo se afirma que "el vínculo hegemónico se 
2.- Esencialmente trataremos de aproximarnos a los planteamientos de Hayek y Mises respecto del trabajo y la organización de los trabajadores en el orden social liberal que proponen ${ }^{37}$, que en resumidas cuentas relegan a un rol menor al trabajo en razón al lugar que ocupa en el orden económico espontáneo o catalaxia ${ }^{38}$, ya que en el mercado la posición preeminente viene dada por aquellos que detentan y ejercen la función empresarial ${ }^{39}$, de la cual depende la circulación de capitales, el descubrimiento de nuevos conocimientos y generación de nuevas tecnologías, permitiendo el avance y creación de riquezas, rechazando por tanto un orden social definido o centrado en el trabajo.

HAYEK comenta que "los puestos de trabajo son, desde el principio, producto del mercado. A la larga, solo el mercado puede ofrecer siempre nuevos empleos, que han de encontrarse constantemente en un mundo cambiante, para mantener a todos aquellos a quienes el mercado facilitó en un principio medios de vida vendiendo su trabajo. Es limitado el número de personas que pueden mantenerse transfiriéndole la renta que los impuestos quitan a otra" 40 .

Más adelante expresa el autor que "es inevitable que los intereses y valores de quienes trabajan por cuenta ajena sean algo distintos de los intereses y valores del que acepta el riesgo y la responsabilidad de organizar la utilización de los recursos. Un hombre que se emplea bajo dirección ajena a cambio de un salario o sueldo fijo puede ser tan concienzudo, laborioso o inteligente como otro que deba elegir constantemente entre diversas posibilidades, pero el primero difícilmente será tan inventivo o

diferencia del contractual en el grado en que la voluntad del individuo puede influenciar al curso de los acontecimientos. Desde el momento en que el interesado opta por integrarse en determinado orden hegemónico, se convierte en un instrumento del jerarca, dentro del ámbito del sistema y por el tiempo del sometimiento". Mises (1986) 303 y ss.

37 Ver: Hayek, Friedrich (1982). "Los principios de un orden social liberal”, Estudios Públicos, No 6, Centro de Estudios Públicos, pp. 179-202.

38 Catalaxia o Cataláctica se utiliza para definir el orden social espontáneo que surge de las relaciones económicas entre individuos bajo un sistema libre de precios de mercado. Según HaYeK, es "el orden que surge por el ajuste recíproco de muchas economías individuales en un mercado". Agrega el autor "Propongo que denominemos a este orden espontáneo del mercado una catalaxia, guardando analogía con el término "cataláctica", que se ha propuesto a menudo como un sustituto del término "económico" (tanto "catalaxia" como "cataláctica" derivan del antiguo verbo griego katallattein que, significativamente, da el sentido no solo de "traficar" y "cambiar" sino también de "admitir en la comunidad" y "convertir de enemigo en amigo". Debemos hacer la observación que tal termino es utilizado de manera sistemática por su maestro Ludwig Von Mises, en su obra "acción humana".

39 Sobre la función empresarial ver: Huerta de Soto, Jesús (2001), Socialismo, Cálculo Económico y Función Empresarial, Madrid: Unión Editorial, 446 pp., p. 41-85; Huerta de Soto (2004) 31 .

40 HayeK, Friedrich (1986), "El paro y los sindicatos en los años ochenta”, en Lecturas de Economía Politica (Coord: Huerta de Soto, Jesús) Vol. 2, Madrid: Unión Editorial, 53-88 pp., p. 55 . 
ingenioso como el segundo, pura y simplemente porque el campo de posibilidades de su trabajo es más limitado" ${ }^{41}$.

En efecto, "las posibilidades ofrecidas a los ricos para invertir lucrativamente sus capitales permitieron que gentes carentes de heredadas tierras y de elementos de trabajo pudieran sobrevivir y reproducirse. Si «el capitalismo ha creado al proletariado", lo hizo al permitir a muchos sobrevivir y tener descendencia. Actualmente el efecto de dicho proceso en el mundo occidental ya no es, desde luego, el aumento del proletariado en el antiguo sentido, sino el crecimiento de una mayoría que en muchos respectos es ajena y a menudo hostil a gran parte de lo que constituye la fuerza impulsora de la sociedad libre" ${ }^{42}$.

Afirma el autor que "el hecho de trabajar en régimen de empleo afecta a algo más que al espíritu de iniciativa e invención de la gente. Estas personas apenas si conocen las responsabilidades que pesan sobre quienes controlan los recursos y han de preocuparse constantemente de adoptar nuevas providencias y combinaciones; hallándose poco familiarizados con las actitudes y formas de vida que engendra la necesidad de tomar decisiones referentes al empleo que haya de darse a los bienes y a las rentas. La persona independiente no distingue de modo tajante entre su vida privada y su vida de negocios, a diferencia de quien ha enajenado parte de su tiempo a cambio de un ingreso fijo". Agrega finalmente que "el trabajo, para aquellos que se encuentran vinculados a un empleo, queda centrado en ajustarse a una estructura dada durante un cierto número de horas, mientras que el independiente trata de modelar y remodelar un plan de vida, buscando soluciones a problemas siempre nuevos. Difieren, sobre todo, el que trabaja en régimen de empleo y el independiente, en sus juicios acerca del concepto de beneficios, de los riesgos a afrontar y en cuanto a la manera de actuar en la vida para alcanzar el éxito con mayor seguridad" 43 .

3.- Desde el punto de vista colectivo, es necesario destacar que tales ideas repercuten en las conclusiones que se obtienen a propósito de la interacción de los sindicatos con los grupos empresariales y como tales se proyectan en el modelo regulatorio de las relaciones laborales en un plano tanto individual como colectivo.

Para estos postulados, la organización sindical o "cooperativa de los grupos de interés", es calificada como "antisocial", siendo equivalente a una "obstrucción y sabotaje sistemáticos de las determinación de los precios a través del mercado competitivo por parte de unos intereses sectoriales organizado a los que se permite emplear la fuerza y coacción

\footnotetext{
41 HaYeK, Friedrich (2008) Los fundamentos de la Libertad, 8a Edición. Unión Editorial S.A., Madrid, pp. 546, p. 163

HAYEK (2008) 160.

43 HAYEK (2008) 163 у 164.
} 
para mantener su monopolio" 44 . Todo en razón de que por la "coacción sindical" se ejerce una ilegítima presión para el aumento del valor del salario de los trabajadores sindicalizados por sobre el incremento del salario real, todo lo cual se genera necesariamente "a costa de los desocupados", forzando a otros obreros y empleados a "permanecer en ocupaciones peor pagadas", lo cual es contrario a "un verdadero mercado libre" ${ }^{45}$. Lo anterior, se fundamenta en la idea de la relación de trabajo de Mises, quien postula que el patrono no puede hacer caridad a costa de la clientela y por ello no puede pagar salarios superiores a los del mercado si los compradores por su parte no están dispuestos a abonar precios proporcionalmente mayores por aquellas mercancías que han sido producidas pagando esos incrementados salarios y no en otros factores externos ${ }^{46}$.

Así, asumiendo que la libertad del que trabaja en régimen de empleo depende de la existencia de un gran número y variedad de empresarios, este solo puede lograrse en un mercado competitivo. Por lo anterior las presiones sobre el mercado por parte de los grupos organizados crean distorsiones, más aún si su monopolio lo erigen sobre la violencia y en desmedro de otras personas, por cuanto se "les han sido concedido con el tiempo privilegios que los ciudadanos corrientes no tienen" ${ }^{4}$, mediante la fuerza "para impedir que otra gente trabaje en los términos en los que trabajan”. Señala el autor que "en especial, la prevención efectiva de todo uso de la violencia por parte de los piquetes debe llevarse a cabo con todo rigor". Agrega "mientras que exista la posibilidad de que unos trabajadores puedan impedir a otros trabajar creo que tenemos una posición intolerable que no es compatible con una economía de mercado operativa. Y estoy convencido de que en un orden de mercado eficiente los sindicatos no pueden tener poder monopolístico de ningún tipo.”

En resumidas cuentas, para esta ideología los sindicatos deberían limitarse a organizar y representar el consenso de los trabajadores frente al empresario/ empleador, debiendo eliminarse cualquier control monopolístico coactivo que podrían detentar en el ejercicio de la actividad sindical por ser distorsionadoras del orden espontáneo del mercado, produciendo "no solo desempleo", sino que también "bajos los salarios de la mayoría de los trabajos".

4.- Estas ideas influyen decisivamente en las propuestas reguladoras de los modelos de relaciones colectivas de trabajo. El caso chileno es el mejor ejemplo a propósito de la normatividad impuesta durante régimen militar de

\footnotetext{
HAYEK (1985) 71.

HAYEK (2008) 362 y ss.

Mises (1986) 374.

Las siguientes citas sin alusión a texto corresponden a las los dichos de HAYEK, Friedrich al ser entrevistado por el Editor Colaborador Thomas W. Hazlett en 1977, poco antes de comenzar su post grado en economía en la Universidad de California, Los Ángeles, encontrándose disponible en https://www.youtube.com/watch?v=-b99S88OiLg
} 
la época y que conocemos comúnmente como Plan Laboral ${ }^{48}{ }^{49}$. En efecto, en nuestro país la estructura de las relaciones de trabajo en su variante colectiva se encuentra limitada por el modelo ideológico de relaciones laborales que la dictadura cívico militar impuso hacia fines de la década del setenta, el cual tuvo por objeto "limitar el poder sindical y, consecuencialmente, la manifestación de la autonomía colectiva. A este efecto, la regulación heterónoma impuesta por el Plan Laboral reguló con dicho objetivo cada uno de los diversos aspectos que importan a la negociación colectiva: sujetos, niveles, titularidad materias, procedimiento de negociación y acuerdos colectivos" 50 .

\section{3) El estado aCtual Del TRABAJO. POSMOdeRNIDAd Y CRISIS ${ }^{51}$}

1.- Las tesis posmodernistas sobre el concepto en análisis se agrupan principalmente dentro del rótulo genérico del debate sobre "el fin del tra-

48 Tal hito regulatorio es englobado comúnmente bajo el rotulo de "Plan Laboral" en 7 Decretos Leyes, a saber: D.L. No 2.755 , No 2.756 , No 2.757 , No 2.758 , o $2.759,2.759,2.760$ y 2.761, publicados en el Diario Oficial entre los días 3 y 7 de julio de 1979, elaboradas por el Ministro del Trabajo de aquel entonces José Pińera Echenique, no obstante que puede afirmarse que esta propuesta ideológica normativa necesitó para configurar su esquema regulatorio la construcción de un escenario previo, tanto en lo fáctico como en lo formal, por lo que estimamos también hacer alusión a otros cuerpos normativos anteriores que configuraron el estado previo preplan laboral y que se caracterizan por su contenido restrictivo y en algunos cosas violentos. Sobre el punto nos referimos especialmente a: BANDO 36 de 18 de septiembre de 1973; D.L. No 12 publicado en el Diario Oficial $\mathrm{N}^{\circ} 28.658$, de 24 de septiembre de 1973; D.L. No 133 publicado en el Diario Oficial N 28.706 de 20 de noviembre de 1973; D.L. No 2.346 publicado en el Diario Oficial de fecha 20 de octubre de 1978; D.L No 2347 publicado en el Diario Oficial con fecha 20 de octubre de 1978; D.L. No 198, publicado en el Diario Oficial el 29 de diciembre de 1973; entre otros.

49 Para una mayor profundización sobre el punto ver: IruRETa URIarte, Pedro (2009). "Regulación de la Libertad Sindical entre 1973-1990" en Libertad Sindical y Derechos Humanos. Análisis de los Informes del Comité de Libertad Sindical de la OIT (1973-1990). Editores Elizabeth Lira y Hugo Rojas. Editorial LOM, primera edición, Santiago, 235 pp.; CaAmaño Rojo, Eduardo (2008), "Las materias objeto de negociación colectiva y la libertad sindical: el fantasma de los "Chicago Boys" a 30 años del plan laboral", en Estudios Laborales, No 3 año 2008, pp. 117-136; Rojas Miño, Irene (2007), "Las reformas laborales al modelo normativo de negociación colectiva del plan laboral", en Revista Ius et Praxis, Vol. 13, No 2, 2007, pp. 195-221; Domínguez Montoya, Álvaro (2013), "Plan laboral y la herencia de la dictadura: análisis crítico al modelo normativo heterónomo de las relaciones de trabajo en Chile, periodo 1973-1990", en mesa 1 NUDO CUERPO/CIUDAD, "Hegemonía, institucionalidad y el proyecto nacional de la dictadura”, en 40 años/Sur El Golpe: Réplicas, Resistencias y Memorias en Diálogo, realizadas el 2 y 6 de septiembre de 2013, en la Universidad de Concepción, Chile.

50 Rojas Miño (2007) 202 y ss.

51 Sobre las teorizaciones posmodernas que defienden las tesis del fin del trabajo, en cuanto a la pérdida de su centralidad en la vida cotidiana, recomendamos ver Gorz, André (1998), Miserias del presente, riqueza de lo posible. Buenos Aires: Editorial Piados, 155 pp.; Castel, Robert (1997), La metamorfosis de la cuestión social. Buenos Aires: Editorial Paidós, 398 pp.; Offe, Claus (1992), La sociedad del trabajo. Problemas estructurales y perspectivas del futuro. Madrid: Editorial Alianza Universidad, 431 pp.; Habermas, Jürgen (1987) Teoría de la acción comunicativa, vol. I. Madrid: Editorial Taurus, 517 pp.; (1989) El discurso filosófico de la modernidad. Madrid: Editorial Taurus, 462 pp., a las cuales se agregan los textos citados con posterioridad; Rifkin, Jeremy (2014) El fin del Trabajo. Barcelona: Paidos, 572 pp. 
bajo”, discusión que puede ser contextualizada en la crisis de 1970 a propósito del progresivo crecimiento de los niveles de desempleo, dando lugar al cuestionamiento del rol y permanencia del concepto de Trabajo asalariado y su importancia dentro de la sociedad moderna, de manera que en este contexto es cada vez menor su valor dentro de las relaciones sociales, circunstancia que anuncia su extinción como categoría histórica ${ }^{52}$.

Sobre el punto Forrester afirma frente a las políticas de gobierno respecto de la crisis del desempleo que "todos se esfuerzan por creer en estos ritos a fin de auto convencerse (aunque con dificultad creciente) de que se trata apenas de una período en crisis, no de una mutación, una nueva forma de civilización organizada, cuya racionalidad supone la anulación del empleo, la extinción de la vida asalariada, la marginación de la mayoría de los seres humanos" 53 .

En tal línea, Dominique Méda nos llama a "desencantar el trabajo" 54 y abandonar su sacralización 55 , descargándolo "de las excesivas esperanzas que le fueron confiadas" 56 , proponiendo liberar el espacio público y replantear la organización del trabajo en miras de dar espacio a otros medios de sociabilidad, otros medios de expresión, otras maneras de adquirir identidad y de participar en la gestión colectiva ${ }^{57}$.

2.- De LA GARzA ${ }^{58}$, con la idea de sintetizar los argumentos de los autores que apuestan por "fin del trabajo", agrupa sus principales ideas en cuatro grupos:

A) La decadencia de la industria en relación con los servicios, como así también el incremento de la estructura de las ocupaciones con crecimientos relativos de los trabajadores calificados o con conocimientos técnicos; la extensión de empleos atípicos como trabajos precarios, así como también los altos niveles de desempleo, han confluido, dando como resultado el incremento de los niveles de heterogeneidad de los trabajadores, lo que repercute en sus normas, valores y actitudes. Es decir "se trata de

52 Neffa, Julio César (2001) "Presentación del debate reciente sobre el fin del trabajo", en El trabajo del futuro. El futuro del trabajo, Compilador Julio César Neffa y Enrique de la Garza Toledo, CLACSO, Buenos Aires, pp. 51-97, pp. 51 y ss.

53 Forrester, Vivian (1997) El horro económico. Buenos Aires: Fondo de Cultura Económica, pp. 1-177, pp. 166 y ss.

54 MÉda, Dominique (1998) El trabajo. Un valor en peligro de extinción. Barcelona: Ed. Gedisa, Col. Hombre y Sociedad (tradud. Marc Valls), 288 pp. Capítulo 10, p. 231. Indica la autora que el trabajo se encuentra "cargado de todas las energías utópicas que se le han atribuido a lo largo de los últimos siglos; el trabajo está encantado en el sentido de que ejerce sobre nosotros una fascinación de la que somos prisioneros. Lo que se impone ahora es romper el hechizo y desencantar el trabajo".

55 MÉda (1998) 239.

56 MÉDA (1998) 238.

57 MÉda (1998) 238.

58 De la Garza, Enrique (1999), “¿Fin del trabajo o trabajo sin fin”, en Castillo, Juan José (ed.), El trabajo del futuro. Madrid: Complutense. $162 \mathrm{pp}$. 
la fragmentación de antiguas identidades obreras que hacen imposible el surgimiento de movimientos colectivos amplios", lo que conlleva la imposibilidad de formación de organizaciones de trabajadores con identidad, lo que impide una propuesta desde la confluencia de sus intereses ${ }^{59}$.

B) La idea del "fin del trabajo" debe ser entendido como el fin de la centralidad del trabajo en el conjunto de las relaciones sociales en la conformación de identidades colectivas. "Se trata de la fragmentación de los mundos de vida, los de los trabajadores ya no son exclusivos de ellos ni tampoco están articulados entre sí. Para los trabajadores los mundos extralaborales se han vuelto más importantes en la constitución de identidades que el trabajo".

C) La pérdida de importancia del trabajo está directamente ligada a su función como generador de valor. En efecto hoy la principal riqueza material de la actual sociedad se crea especulativamente en el sector financiero, por lo que no depende del trabajo. Así "en la sociedad posindustrial es prescindible el trabajo y por lo tanto los trabajadores, el capital ya no tiene nombre; se trata ahora de los fondos de pensiones pertenecientes a miles de pequeños ahorristas con un carácter más especulativo que productivo, es decir la riqueza social ya no depende del trabajo" ${ }^{60}$.

D) La crisis del trabajo es un problema esencialmente político, "resultado de una lucha que se perdió desde los ochenta", lo que ha implicado el tránsito hacia el neoliberalismo, la restructuración productiva y la flexibilidad laboral en sus diversas variantes, factores que inclinan la balanza en perjuicio de las organizaciones obreras, transformando la lucha de clases en la lucha de los mercados y las empresas. En efecto "la decadencia del movimiento obrero se debe principalmente al triunfo de las estrategias de los empresarios para ganarse a los trabajadores y hacerles ver que el enemigo no es el capital sino las empresas competidoras en el mercado; también es por la transformación del estado hacia el liberalismo, que ha reducido espacios de acción de los sindicatos y ha apoyado a las empresas en la flexibilidad del mercado de trabajo"61.

3.- Dentro de este grupo de autores puede ser mencionado HaBerMAs, el cual no obstante lo anterior y lo complejo de sus planteamientos en su "teoría de acción comunicativa", merece una mención especial. Señala el autor que "el trabajo ya no es una categoría de explicación dominante de nuestra sociedad, si por trabajo se entiende una praxis particular que consiste en oponerse el hombre a la naturaleza para transformarla y en consecuencia, al mismo tiempo transformase a si mismo" 62 . Afirma lo anterior señalando que "en cuanto las energías utópicas, ellas no se han

\footnotetext{
59 De La Garza (1999), 758.

60 De La Garza (1999), 759.

61 De La Garza (1999), 759.

62 Cita de Neffa (2001), 59.
} 
retirado absolutamente de la conciencia histórica. Es más bien una cierta utopía que llega a su fin, aquella que en el pasado se había cristalizado alrededor del potencial que residía en la sociedad del trabajo"63. Agrega que la "utopía del trabajo de la sociedad del trabajo perdió su fuerza persuasiva", "perdió su punto de referencia en la realidad: la fuerza estructurante y socializadora del trabajo abstracto".

Lo anterior tiene implicancias en el desarrollo de los postulados de Habermas por cuando propone el "fin del paradigma de la producción" sustituyendo el mismo por el "paradigma de la comunicación", argumentando que no es la actividad laboral la fuerza transformadora y estructurante de la sociedad que permita la desalienación sino que su lógica organizacional es la que da tales espacios, como acción instrumental y hoy en día el trabajo por su definición a la luz de los modos de producción no puede ser considerado creador ni autorrealizador, y por ello no hay en él un potencial emancipador, por que "el acento utópico se traslada al concepto de la comunicación" 64 .

\section{2) Derecho del Trabajo Moderno: Contextualización Y CLAVES PARA SU ENTENDIMIENTO}

\section{1) El DeRECHO, El Derecho Del trabajo y algunaS APROXIMACIONES CRÍTICAS PARA SU COMPRENSIÓN}

1.- Desde una óptica jurídica el Derecho del Trabajo recibió, como otras ramas del derecho, la influencia decisiva de los planteamientos positivistas kelsenianos ${ }^{65}$, lo que desde nuestro punto de vista ha permeado profundamente las posturas ius laboralistas respecto del fenómeno del trabajo, lo que ha producido perniciosas consecuencias en el análisis y desarrollo de estos estudios al descartar de su conformación la matriz política y el conflicto connatural de los mismos. De allí arranca entonces la necesidad de reincorporar lo político conflictual a las relaciones de trabajo desde una comprensión crítica de lo jurídico. Lo anterior no porque se

\footnotetext{
63 Cita de NefFa (2001), 59.

64 Habermas, Jürgen (1988), "La crisis del Estado de bienestar y el agotamiento de las energías utópicas”. Ensayos políticos. Barcelona: Península, 113-134 pp., p. 133.

65 Kelsen, Hans (2005), Teoría pura del derecho (trad. de R. Vernengo). Buenos Aires: Porrúa, 358 pp. Respecto de las interpretaciones y críticas realizadas por Kelsen a las ideas de Marx, ver. Guastini, Ricardo (1982), "La ambigua utopía. Marx criticato da Kelsen”, en Revista Sociologia del Diritto, 2, pp. 5 y ss. (trad. Huerta Bortolotti, Agustín; Correa, Óscar, Centro de Traducciones de la UAP), Guastini, Ricardo (1989), "Kelsen y Marx”, en Óscar Correa (Coordinador), El otro Kelsen, D.F.L, Universidad Nacional Autónoma de México, pp. 79-98; Ruiz Manero, Juan (1986), Sobre la critica de Kelsen al marxismo, Doxa 03, pp. 191-231.
} 
busque destacar la conflictividad como una característica interesada de los autores, sino por el contrario, busca contribuir al entendimiento del fenómeno del trabajo y poder diseñar desde el punto de vista jurídico un modelo de regulación que satisfaga los requerimientos de la sociedad moderna fundada en la contradicción y el conflicto como aspecto esencial de la misma ${ }^{66}$.

Sin embargo, advertimos la complejidad de esta opción, al incluir dentro del objeto del Derecho del Trabajo materias que son el objetos de otras disciplinas (economía, política, sociología) obliga al jurista a relacionarse con dichos conceptos, lo que constituye un desafío para la doctrina laboral actual.

2.- En este esquema, y no obstante que las concepciones sobre el Derecho desde una perspectiva crítica son escasamente unívocas ${ }^{67}$, existe cierta uniformidad en que el Derecho es un fenómeno de las sociedades divididas en clases o grupos sociales, que poseen características que lo distinguen los unos de los otros y guían su acción dentro de la comunidad, no siendo por tanto el derecho un fenómeno socialmente indiferente y falto de caracterización, no pudiendo entenderse como una mera técnica. En efecto, el Derecho no puede comprenderse por sí mismo haciendo abstracción de la vida real, ya que su existencia deriva de las condiciones materiales y subjetivas de la sociedad civil en conjunto con las relaciones de producción, las cuales evocan relaciones de poder. En otras palabras las relaciones jurídicas giran principalmente alrededor de las relaciones de producción y propiedad privada como modeladores de dichas relaciones en un momento histórico determinado. Esta evolución no solo alcanza al Derecho del Trabajo, sino también al ámbito civil, en cuanto la contratación común ha ido incorporando un estatuto protector al contratante débil ${ }^{68}$.

66 Ver Dávalos Morales, José (1997), "Conflictos del Trabajo", en Instituciones de Derecho del Trabajo, Academia Iberoamericana de Derecho del Trabajo y de la Seguridad Social. D.F.:UNAM, pp. 215-250. En un plano teórico general a propósito del conflicto como motor de la sociedad y su evolución. Simmel, George (2010) El conflicto. Sociología del antagonismo (traducción de Javier Eraso Ceballos). Madrid: Edit. Sequitur, 96 pp.; Coser, Lewis (1970) Nuevos Aportes a la Teoría del Conflicto Social. Buenos Aires: Amarrortur, 249 pp.; McNeiL, B. Elton (1975), La naturaleza del conflicto humano. D.F.: Editorial FCE., 406 pp.; BaLANDIER, Georges (1993) El desorden. La teoría del caos en las ciencias sociales. DF.: Editorial Gedisa, 237 pp.; Fromm, Erick (1986) Anatomía de la destructividad humana. D.F., Editorial S. XXI, 507 pp.

67 Ver Valqui Cachi, Camilo; Pastor BazÁn, Cutberto (Coordinadores), (2009). "Corrientes Filosóficas del Derecho: una crítica antisistémica para el siglo XXI”, Cajamarca, Facultad de Derecho y Ciencia Política, Universidad de Cajamarca, 2009, 140 pp. ; Воввіо, Noberto (2001), 189 y ss.

68 Como se puede apreciar en nuestro país en la contratación que surge de la relaciones del consumo y que se regulan en la ley No 19.496 sobre Protección a los Derecho de los Consumidores. 
Por lo mismo, creer que la actual sociedad capitalista descansa sobre leyes jurídicas es una ilusión. Idealmente debe ser la ley la que debe asentarse sobre la sociedad, debiendo representar los intereses de una época determinada condicionada por factores culturales, políticos, sociales y económicos, no existiendo por tanto un orden legal creador. El Derecho no se basta a sí mismo, no contiene su propio principio de explicación, sino que se reconduce a otro factores, particularmente políticos y económicos, no obstante que ambos intervienen en la constitución y funcionamiento de las relaciones sociales representándolas muchas veces de manera deformada. Sobre este punto Jeammaud indique que ello: "no significa en modo alguno que esta representación sea una simple argucia para engańarnos en cuanto a la naturaleza verdadera e inconfesable de las relaciones de explotación, sino todo lo contrario, este disfraz aparece como una condición propia de la constitución, del funcionamiento y de la reproducción de estas relaciones. De esta manera, la estructura económica del capitalismo no existiría si no existiese el Derecho o, cuando menos, un cierto tipo de Derecho -el derecho normativo- con sus reglas generales que hablan de sujetos abstractos, libres e iguales. Puede afirmarse que esta "visión jurídica" de las cosas es una dimensión interna de las relaciones de producción, más que decir que es producto y que ese derecho burgués sean el modo de existencia histórico de cierto contenido: Las relaciones de producción específicas del capitalismo, que no podrían establecerse ni reproducirse sin esta forma" 69 .

3.- Incluso si se quiere, más allá del desentrañamiento de qué es el derecho o la pretensión de una teoría general del derecho ${ }^{70}$, es mayormente ilustrativo observar cómo se comporta en cuanto fenómeno político-social, siendo más bien una representación jurídica discursiva del poder que contiene una hipótesis engañosa sobre su funcionamiento, de acuerdo a FoucaulT ${ }^{71}$.

Para el autor anterior, históricamente, el edificio jurídico de nuestras sociedades se construyó a pedido del poder y también en su beneficio, para servir de instrumento o justificación ${ }^{72}$ y por lo mismo no ha de

69 Jeammaud, Antoine (1986), "La Critica del Derecho en Francia”: De la búsqueda de una teoría materialista del derecho al estudio critico de la regulación jurídica en MiaILle, Michel et al. (1986), pp. 51-52.

70 Bоввio, Noberto (2001) Marx y la teoría del Derecho. DF: Fondo de Cultura Económica. pp. 1-283, pp. 185-197;

Poulantzas, Nicos, et al. (1970), Hacia una teoría marxista. Cali: Nueva era, 90 pp.; CeRRONI (1965).

71 Foucault, Michel (2008) Historia de la Sexualidad. Vol. 1. La Voluntad de Saber, 2a ed., trad. U. Guiñazú. Buenos Aires: Siglo XXI, 2008, 152 pp., pp. 17; 79

72 Foucault, Michel (2008), Nietzsche, la Genealogía, la Historia, 6a ed., trad. J. Vásquez Pérez, Valencia: Pre-textos, 76 pp., p. 36; (2006) Defender la Sociedad. Curso en el Collège de France (1975-1976), 2a ed., trad. H. Pons. D.F.: FCE, 290 pp.; pp. 35; 42; 43; (1999) "Las 
extrañar que el Derecho del Trabajo reproduzca esa lógica ${ }^{73}$. En este sentido, el derecho es producido, modificado y transformado por intereses de ciertas personas, clases, grupos o sociedades completas en el ejercicio mismo del poder con el objeto no solo de reprimir, castigar y dominar, sino también como productor de una única verdad y recreador de lo real mediante el paradigma del saber ${ }^{74}$, por cuanto "detrás de todo saber o conocimiento lo que está en juego es una lucha por el poder. El poder político no está ausente del saber, por el contrario, está tramado con este"75.

En esta postura el derecho es instrumentalizado por el poder, se vuelve difuso, lo justifica y lo convierte en verdad mediante la noción de orden y objetividad, al permitir y condicionar ciertas prácticas y relaciones de poder produciendo discursos de verdad" ${ }^{76}$, siendo el derecho "la máscara del poder"77, 78 .

En un plano iuslaboralista tales cuestionamientos no han quedado fuera de discusión, particularmente desde una corriente revisionista en sus diversas variantes ${ }^{79}$, pero particularmente de aquellas de intención desmitificadora ${ }^{80}$ y de variante más especulativa y técnica ${ }^{81}$, planteamientos que en general tratan de entender y explicar las relaciones sociales derivadas de las relaciones de trabajo desde una dimensión compleja, en el que las determinaciones económicas son estructuras prácticas que contienen dentro de si un universo ideológico inmerso en relaciones sociales de

mallas del poder”, en Estética, ética y hermenéutica. Obras esenciales. Vol. III. Barcelona: Paidós.; p. 237; Foucault, Michel (2008), 84 y ss.

73 Ver Palomeque (2002); Romagnoli (1997).

74 Foucault, Michel (2004), "Poderes y Estrategias", en Un diálogo sobre el poder y otras conversaciones, $1^{\text {a }}$ reimp. Madrid: Alianza Editorial, 176 pp., p. 137.; (1996), Genealogía del racismo. Cantabria: Altamira Press. 220 pp., p. 35.

75 Foucault, Michel (1996), La Verdad y las Formas Jurídicas, 2a Ed. corregida, trad. Enrique Lynch. Barcelona: Ed. Gedisa, 1-168 pp., p. 59.

76 Foucault, Michel (1999), "La Ética del Cuidado de sí como práctica de la Libertad", Obras Esenciales Estética, Ética y Hermenéutica, volumen III, trad. A. Gabilondo. Barcelona: Paidós, 223 pp., p. 1-44.

77 Foucault (1999), 410; Foucault (2008) 17, 18.

78 En sentido similar, KAHN-FreUnd señala "el derecho necesita contemplar las relaciones de subordinación en términos de coordinación, esto es presentar un acto de sumisión bajo la máscara de un contrato, porque es a través de esta ficción, como las leyes conjuran la pesadilla del trabajo forzoso". KaHn-Freund, Otto (1987), Trabajo y Derecho, $3^{\text {a }}$ edición, trad. Jesús M. Galiana Moreno, Ministerio de Trabajo y Seguridad Social, Madrid, 482 pp., p. 60.

79 Término acuñado por BARbagelata al referirse al revisionismo en la doctrina laboral de carácter crítico. BARBAGElata (2009) 223 y ss.

80 El mismo autor dice que "desmitificar viene del idioma francés, expresa la acción de desenmascarar al mistificador, o sea al que engaña, falsifica o disfraza un hecho o una idea. Desmitificar es poner en relieve la falta de fundamento de la excesiva estima concedida a personas, ideas, instituciones, etc.” Barbagelata (2009) 237 y ss. En esta línea ver Courtois, Sinzheimer, Jeammaud, Edelman, lyon Caen, Mario de la Cueva, Carofalo, Kahn-Freund.

81 Martin Valverde, Supiot, Romagnoli, Palomeque y Baylos entre otros. 
producción ${ }^{82}$, no quedando el derecho ajeno de la estructuras definidas por las relaciones de poder.

\section{2) La perspectiva contractualista del Derecho Del TRABAJO}

1.- En esta perspectiva, y dado el predominio de una visión laboral fundada en la relación patrono-trabajador, se hace necesario formular reflexiones respecto de la concepción individualista del trabajo, caracterizada en la disciplina como un capítulo fundamental de esta y que se conoce como el Derecho Individual del Trabajo o Derecho Contractual del Trabajo. Este capítulo, se sustenta en el reconocimiento de los sujetos intervinientes como propietarios privados en una relación jurídica formal, cuya exteriorización es el contrato legalmente celebrado, siendo una relación de voluntades que refleja la relación económica real, quedando el contenido de tal relación dado por la relación económica, funda en relaciones de producción.

En esta construcción liberal, el hombre, en el plano de las relaciones materiales de vida y una vez disueltas aquellas trabas impuestas por el sistema feudal, se determina en su interacción por la "razón", relacionándose los individuos "libres" mediante pactos que determinan la solución a sus conflictos sociales mediante el contrato como expresión máxima de la libertad individual, resultando por tanto el derecho no como una cuestión impuesta, sino más bien como un ejercicio concursal de voluntades autónomas, destacando la horizontalidad de los contratantes y el consentimiento mutuo como fundamento del contrato. Lo anterior aplicado al mundo del trabajo, permite igualar -formal y aparentemente- al empresario y trabajador como seres libres y autodeterminados que se desenvuelven en el contrato como tales, siendo el mercado un reino de igualdad, porque cada uno entra en relación con otro como un simple propietario de mercancías, e intercambia equivalente con equivalente ${ }^{83}$.

Para esta perspectiva, se habla que el trabajador ilusoriamente consiente libremente en ceder su trabajo, siendo doblemente libre en cuanto no tiene amo y no es sometido a la esclavitud y, por otro lado, es libre en la elección del medio de producción que le permita vivir. Es ilusoria por que "el trabajador, en cuanto propietario solo de su fuerza de trabajo inmediata, no puede, mediante su consentimiento voluntario, entregar su libertad y se somete a otro sin coerción, en uso de su razón autónoma

\footnotetext{
82 Rochabrún, Guillermo (2007), Batallas por la Teoría, en torno a Marx y el Perú. Lima: Editorial IEP, $565 \mathrm{pp}$.

83 Wood, Allen (1989), "Marx y la igualdad" en "El marxismo una perspectiva analitica" John E. Roemer (compilador), Fondo de Cultura Económica, D.F. pp. 321-342, p. 323.
} 
y solamente en virtud de ese consentimiento" 84 , originándose la relación de trabajo "como un acto de sumisión que en su dinámica produce una situación subordinada, por más que la sumisión y subordinación puedan ser disimuladas por esta indispensable ficción jurídica conocida por contrato de trabajo" 85 . En este mismo sentido Wood indica que "lo irónico de la situación capitalista es que esta igualdad, lejos de proteger a los trabajadores de la opresión, resulta ser, precisamente, el medio a través del cual se lleva a cabo la opresión del trabajador asalariado" 86 .

Es así como el trabajo se canaliza jurídicamente mediante la formacontrato, en la que "la igualdad formal entre las partes constituirá de esta manera una función de la desigualdad sustancial entre estas", reproduciendo la "desigualdad de los poseedores" y reforzando la "invisibilidad de los poderes económicos y políticos que lo determinan”, exigiendo mediante la fórmula de la paradoja que "las situaciones de subordinación aparezcan como relaciones de coordinación entre seres libres e iguales; necesita que un acto de sumisión se presente bajo la máscara de un contrato" 87 .

De tal manera, las relaciones sociales de los hombres en el proceso de producción revisten una forma cosificada, que se materializa en los productos del trabajo humano, los cuales le asignan un valor de cambio, constituyendo de esta forma de intercambio el momento de su realización. Por eso, el derecho tiene como sustento fáctico, que al reconocerse como propietarios en el intercambio de las mercancías, los hombres aparecen como sujetos jurídicos, autónomos y libres, dado que el intercambio generalizado causa la abstracción de la relación y de los sujetos que la realizan.

2.- Este esquema cambiario patrimonial constituye la expresión misma de la construcción liberal inserta en la relación de trabajo y en el mundo de los contratos, sometiendo tal relación social a los planteamientos básicos del Derecho Civil. El problema claramente radica en la configuración real de la relación laboral, requiriendo la incardinación del modelo laboral dentro de una relación obligacional de patrono-obrero en un modelo contractualizado suministrado por el derecho privado. Esto calza con la figura del arrendamiento de servicios que posteriormente evoluciona a un modelo que reconozca con una relativa independencia, la debilidad de los contratantes, dando nacimiento al contrato de trabajo como una figura autónoma a su antecedente civil.

\footnotetext{
84 Baylos, Antonio (1991), Derecho del Trabajo: modelo para armar. Madrid: Editorial Trotta, 158 pp., p. 20

Kahn-Freund (1987) 53.

Wood (1989) 323.

Baylos (1991) 20. En similares términos Khan-Freund (1987) 60.
} 
El intercambio por medio del contrato, constituye la primera categoría de la que el sujeto no es sino un derivado, constituyendo un mecanismo eficiente dentro del capitalismo que permita resolver la contradicción entre sujetos y por ende, de sectores antagónicos, siendo evidente la conexión entre ambas en la cual la primera avanza a la par con la segunda. Para esta postura el orden jurídico debe garantizar los resultados del encuentro de voluntades entre el que compra trabajo y el que lo ofrece.

3.- Por lo anterior, el contrato de trabajo nació en un contexto de desigualdad, en la que se perpetúa la esencia de las relaciones de dominación. No obstante, los esfuerzos de la doctrina laboralista de revestir de bondad una relación desigual ha generado en más de una oportunidad la interrogante de si es posible superar la cosificación del trabajo dentro del mismo sistema de producción capitalista. Diría Supiot “aún hoy en día, muchos juristas detestan reconocer que, por medio del contrato de trabajo, el asalariado compromete su propio cuerpo en un relación patrimonial. Sin embargo, la evidencia de este compromiso y de los peligros que encierra ha constituido, en todas partes, la piedra angular del derecho del trabajo y la razón de autodenominación con respecto al derecho común de las obligaciones" 88 .

4.- En el derecho laboral de nuestro país, se ha impuesto una postura contractualista de la relación de trabajo y ello corresponde a una evidente revitalización de la autonomía contractual propia del modelo de economía adoptado en las últimas décadas, la cual no necesariamente implica una posición desventajosa para el trabajador. En efecto, el contractualismo representa un obstáculo para ciertas posiciones comunitaristas de la relación laboral, que han sido recepcionadas por la jurisprudencia ${ }^{89} \mathrm{y}$

$88 \quad$ Supiot (1996) 30.

89 Sentencia de la Corte Suprema del 19 noviembre de 2010. ROL No 5.485-2010. Gutiérrez Puebla Fabián con Linker S.A. "Que, como lo ha declarado esta Corte en otras oportunidades el contrato de trabajo se caracteriza también por su contenido ético, es decir, por el imperio de ciertos principios que las partes deben respetar, entre ellos, el deber de fidelidad y lealtad que a ambas se encuentran obligadas. Por lo mismo las relaciones laborales han de desenvolverse en un clima de confianza". En similar sentido "El contrato de trabajo se encuentra marcado por su contenido ético, es decir, por el imperio de ciertos principios que las partes deben respetar, entre ellos, el deber de fidelidad y lealtad a que ambas se encuentran obligadas, atendidas, entre otras, las circunstancias de alta competitividad en la que se desarrollan en el mundo moderno las actividades empresariales. En efecto, el mayor o menor éxito de una empresa radica en la calidad y variedad de los productos que ofrecen a los consumidores de los mismos, características que, a su vez, dependen de un acertado proceso de producción en el que, sin duda, los dependientes juegan un rol principal”. 23 de julio de 2009. ROL 3599-2009. Tapia Tono, Evelyn con Banco de Crédito e Inversiones. De igual forma se ha dicho "Que, como lo ha declarado esta Corte en otras oportunidades, el contrato de trabajo se caracteriza también por su contenido ético, es decir, por el imperio de ciertos principios que las partes deben respetar, entre ellos, el deber de fidelidad y lealtad a que ambas se encuentran obligadas. Por lo mismo, las relaciones laborales han de desenvolverse en un clima de confianza, el que se genera en la medida que las partes cumplan con sus obligaciones en la forma estipulada, de buena fe, principio del cual se encuentra imbuida toda 
doctrina laboral ${ }^{90}$ en el sentido que el contenido ético y la buena fe se introducen como elementos normativos indeterminados en la ponderación del cumplimiento de las obligaciones laborales, ideas que hacen impreciso el contenido obligacional del vínculo, debilitando los derechos del trabajador y sobre todo en el ámbito de sus derechos constitucionales ${ }^{91}$.

\section{3) Las funciones del Derecho del Trabajo: la Protección Y LA PACIFICACIÓN SOCIAL}

1.- En un plano normativo más general, este derecho como rama jurídica se origina en la profunda desigualdad social generada durante la sociedad industrial, definiendo desde su origen su principal objetivo que es el de proteger al trabajador ${ }^{92}$. En efecto, el Derecho del Trabajo encuentra su origen en la incapacidad de la regulación del fenómeno laboral por parte del Derecho Civil, destinado a superar aquella insuficiencia reglamentaria de la prestación del trabajo definida por la estructura obligacional patrimonial y el fundamento individualista en que descansa la autonomía de la voluntad, determinada por la interacción de los sujetos libres en un contexto de horizontalidad ficticio: "La sociedad libre fue comprendiendo que no todos los hombres se ajustan a la imagen ficticia del individualismo, abriendo así el derecho social su primera brecha en la

la legislación nacional y consagrado, especialmente en materia contractual, en el artículo 1546 del Código Civil.

De esta manera, los mencionados deberes integrantes de la carga ética aludida, son claras directrices del comportamiento de los contratantes durante la vigencia de su vinculación, sujetándolos a varias obligaciones que, con independencia de su explicitación en el texto del contrato pertinente o consensuados expresamente, emanan de la naturaleza de la relación laboral." Sentencia Corte Suprema de fecha 19 de noviembre de 2010. ROL 5485-2010. "Gutiérrez Puebla, Fabián con Prosegur Chile S.A.".

En similar sentido ver Sentencia Corte Suprema, fecha 20 de octubre de 2011. ROL 93132010. Gallardo Cabello Elizabeth con Lan Airlines S.A.; Sentencia Corte Suprema de fecha 22 de julio de 2009. ROL 2319-2009, Acevedo Bustos Manuel Alejandro con Corporación de Asistencia Judicial.

90 Véase Thayer Arteaga, William - Novoa Fuenzalida, Patricio (1980) Manual de Derecho del Trabajo. Santiago: Editorial Jurídica de Chile. T. III 580 pp., p. 335 ss.; de manera matizada, reconociendo un contenido dual Gamonal Contreras, Sergio (2005) Daño moral en el contrato de trabajo. Santiago: LexisNexis. 175 pp., p. 11; (2004) Ciudadanía en la Empresa. Montevideo: FCU. 77 pp., p. 72-73.

91 Melis Valencia, Christian (2010). Los derechos fundamentales de los trabajadores como limites a los poderes empresariales. Santiago: LegalPublishing. 154 pp., p. 39. Ugarte Cataldo, José Luis (2011). "Los derechos fundamentales del trabajador y la buena fe en el debate español" en Revista de Derecho de la Pontificia Universidad Católica de Valparaíso, No 36, 1a Semestre, pp. 141-164.

92 Sobre este punto ver los postulados clásicos de la finalidad y objeto del derecho del trabajo, en cuanto protección del trabajador ver Pla Rodríguez, Américo (1975) Los principios del Derecho del Trabajo. Montevideo: Depalma. pp. 1-333; Ermida Uriarte, Óscar (2001) "Protección, igualdad, dignidad, libertad y no discriminación DL no 241". Derecho Laboral, No 241 vol. 54, (ene/mar 2011), p. 7-23. 
legislación contra la usura, consolidándose con posterioridad por medio de las limitaciones que se establecieron a la libertad contractual a fin de proteger la fuerza de trabajo, al individuo económicamente débil" 93 .

En tales situaciones, el trabajador, dada su debilidad económica y su vital requerimiento de obtener y asegurar un puesto de trabajo que le permita proveer su subsistencia y la de su familia, no disfruta efectivamente de la posibilidad de concertar libremente sus condiciones de trabajo, sino que se ve constreñido a aceptar las impuestas unilateralmente por el empleador, con el consecuente resultado de injusticia social ${ }^{94}$. Así, para algunos el Derecho del Trabajo cumple una función tutelar frente al trabajador, ya que "lo protege frente al poder económico para que no sea absorbido por él" 95 , que se expresa en la idea de "reducir la desigualdad propia de la relación de trabajo o para evitar los peores efectos de esa desigualdad. Así la desigualdad es el fundamento último de la protección. Si no fuera por ella, la protección no se justificaría" 96 .

La finalidad protectora antes señalada, que podemos calificarla de optimista, hoy debe ser seriamente puesta en duda, ya que bajo una perspectiva liberal-económica, la regulación y protección del trabajo no puede ser de tal entidad que impida o desincentive el desarrollo de la empresa ${ }^{97}$, en concordancia con la particular influencia producida por la descentralización económica y la flexibilidad económica producida ${ }^{98}$

93 Gamonal, Sergio (2008), Fundamentos de Derecho Laboral. Santiago: Editorial LexisNexis, 162 pp., p. 11.

94 ERMida Uriarte, Óscar; Hernández Állvarez, Óscar (2003). “Critica de la subordinación”, en Estudios jurídicos en homenaje al doctor Néstor de Buen Lozano. D.F.: UNAM, pp. 269-297.

95 Amauri Mascaro, Nascimento (1999) Teoría General del Derecho del Trabajo, São Paulo, LTR, pp. 358, p. 68-69.

96 Ermida Uriarte, Óscar (2011) Meditación sobre el Derecho del Trabajo. Cuadernillos de la fundación Electra, p. 8.

97 Dualidad reconocida por Martínez Vivot, Julio (1994), Elementos de Derecho de Trabajo y de la Seguridad Social, 2a. Ed., Buenos Aires: Editorial Astrea, 787 pp., p. 34 . Que nos dice que "el respeto por la dignidad del hombre que trabaja, y, por ello, pretende crear un orden que facilite el ejercicio de su actividad con plena dignidad y con respeto hacia su persona"; que no se hace contra alguien o contra una estructura, cuidando, por el contrario, que no se lesione "el funcionamiento o la propia organización de la empresa".

98 Debido a lo anterior la flexibilidad de "utilidad" no ha estado ausente de la reglamentación del derecho del trabajo, toda vez que ha sido adoptada como un concepto más bien neutro respecto de los contratantes, proyectándose como mecanismo de entrada, de ejecución y de salida de la relación de trabajo. Durante la ejecución, la flexibilidad contribuye a la funcionalidad del contenido obligacional y aquí no se presentan grandes críticas, sin embargo en el régimen de entrada y salida del contrato, es donde se produce la mayor controversia. Normalmente precarizar y despedir. Ahora, si bien los conceptos sobre flexibilidad laboral son abundantes, podemos entenderla en nuestra materia como "la debilidad de las restricciones jurídicas que regulan el contrato laboral y, en particular, las decisiones de despido." Boyer, Robert (1986) La flexibilidad del trabajo en Europa. Madrid: Centro de publicaciones ministerio del trabajo y seguridad laboral, 372 pp., p. 280 . Sobre el punto ver UGarte Cataldo, José Luis (2004) Derecho del Trabajo, flexibilidad laboral y análisis económico del derecho. 
en materia laboral o en su variante más sofisticada como flexiseguri$\operatorname{dad}^{99}$.

2.- Desde esta postura es útil fijar como punto de partida que el Derecho del Trabajo desde su creación ha cumplido una ambivalente función ${ }^{100}$ : ser el soporte al modelo económico capitalista mediante la regulación y pacificación del conflicto social propio del reparto de la utilidad social agregada entre los titulares del capital y del trabajo, encausando de manera pacífica la regla jurídica, permitiendo la consolidación del sistema económico dominante y por otro lado de modo simultáneo, ha prestado servicios al modelo político democrático al aumentar de manera progresiva la participación y visibilidad política de los excluidos y marginados por la sociedad, mediante los distintos procesos de reivindicación social ${ }^{101}$.

Santiago: LexisNexis, 116 pp.; ERmidA, Óscar (2001) La flexibilidad. Montevideo: Fundación de Cultura Universitaria, 78 pp.

99 Tradicionalmente la Flexiseguridad ha sido entendida como la combinación de "una baja protección laboral (especialmente para despedir) con subsidios para los desempleados, más una política activa de alto nivel en mercado de trabajo". Sobre el punto ver Gamonal ConTRERAS, Sergio (2011), "Flexiseguridad: mitos y desafíos" en Trabajo y Derecho. Santiago: LegalPublishing, pp. 1-223., pp. 191-206. Para un análisis critico ver Gorelli Hernendez, Juan (2013). "Critica a la flexiseguridad". Revista Latinoamericana de Derecho Social, No 16, enero-junio, pp. 51-82.

100 Planteamiento atribuido a Lyon CAEN, en cuanto el derecho del trabajo no es exclusivamente protector de los trabajadores, sino que también beneficia a los empleadores. Señala este autor que "no hay mercado sin principios del derecho del trabajo". Señala el autor al hacer un análisis de la diversidad del materialismo histórico de comprender Derecho del Trabajo que "Sin querer asimilar los puntos de vista fundamentalmente diferentes, algunos pondrán de manifiesto el paralelismo de los análisis hechos. El Derecho del Trabajo podría no ser más que gran beneficio del liberalismo o puro instrumento de la burguesía. No obstante, hay que restituir a lo cotidiano su realidad, a la luchas su función, y a la ambivalencia del derecho del trabajo su existencia”. Camerlynk, G.H.; Lyon- Caen, G., (1974) 119.

101 Ugarte Cataldo, José Luis (2007), El nuevo Derecho del Trabajo. Santiago: Editorial LexisNexis, 262 pp., p. 19 y ss. En el mismo sentido Gamonal (2008) 12 y ss. Este planteamiento puede, a nuestro criterio, englobarse dentro de aquellas posiciones que sostienen que el Derecho puede constituir una herramienta de emancipación, en tanto que ciertas condiciones sociales, económicas o políticas se den como elemento previo y, que a su vez garanticen sus propias posibilidades emancipadoras (CÁrdennas Rivera, Miguel (2004) Justicia pensional y neoliberalismo: Un estudio de caso sobre la relación. Bogotá: Editorial ILSA, 278 pp., p. 30 y ss.). Se reconoce, así, que es posible el uso del derecho como un arma para el cambio social donde "seguramente un derecho acompañado de poderosas políticas públicas y económicas pueda llevar a un cambio. De todas maneras, sin una base material distinta a la actual, todo el discurso del derecho se quedará en las nubes, incluso atentando e impidiendo una posible transformación". En línea similar, se plantea que las posibilidades de emancipación que el derecho ofrece, en particular, son cuando este se construye a partir de la jurisprudencia de los Tribunales de Justicia en un contexto caracterizado por la debilidad de los movimientos y la crisis de la representación política, donde se observa que esta entidad judicial entre a suplir esos vacíos a través de sus decisiones (García Villegas, Mauricio; Uprimmy, Rodrigo (2004), "Corte Constitucional y Emancipación Social en Colombia", en De Sousa Santos, Boaventura y García Villegas, Mauricio (editores), Emancipación Social y Violencia en Colombia. Bogotá: Editorial Norma, 621 pp.). 
Como anota Palomeque y Álvarez, "todas las sociedades históricas han conocido la realidad del trabajo productivo por cuenta de otros, así como los conflictos sociales derivados de este hecho, y si, sin embargo, el Derecho del Trabajo como disciplina propia no aparece hasta un determinado momento en la evolución de la sociedad (capitalismo industrial), es incuestionable que la aprehensión de la verdadera esencia de este ordenamiento jurídico exige la determinación de las causas que hicieron posible, en un determinado momento histórico y no en otro, la aparición de un nuevo cuerpo normativo que daba respuesta a nuevas exigencias sociales. Todo ello tiene que ver, naturalmente, con el fundamento del Derecho del Trabajo y la identificación del singular conflicto social que se encuentra en su base y sobre el que aquel ejerce su virtualidad integradora. Fundamento y objeto de la disciplina son por ello realidades científicamente inescindibles en la contemplación de la noción y de la función normativa del Derecho del Trabajo, bien que configuren desde luego planos diversos de una misma realidad institucional" 102 .

Si observamos la razón social histórica del Derecho del Trabajo responde a la necesidad social de canalizar el conflicto político surgido entre los nuevos antagonistas colectivos del sistema económico, cumpliendo con la trascendental misión de imponer a la contradicción de intereses un cauce de circulación compatible con la permanencia y el desarrollo del sistema de producción capitalista y las paredes maestras de la sociedad burguesa liberal ${ }^{103}$. Por lo demás es claro que el Derecho del Trabajo legaliza las relaciones de trabajo y solo limita el poder patronal, no siendo su fin "modificar la naturaleza de las relaciones de trabajo"104.

En relación a la función del Derecho del Trabajo, Palomeque y Álvarez nos dicen que "el Derecho es ciertamente una técnica instrumental de organización social establecida para la integración, institucionalización o juridificación de los conflictos sociales. A través de la norma jurídica se impone el cauce adecuado para la solución ordenada del conflicto (individual o colectivo), configurándose de este modo un sistema de seguridad y conservación de las relaciones sociales vigentes en un momento determinado. El conflicto de intereses es por ello una realidad social preformativa, que el Derecho viene precisamente a integrar. La conflictividad social es canalizada jurídicamente de acuerdo con el cuadro de intereses y valores propios de la opción política que expresa la norma jurídica en cuestión, que no son naturalmente sino los del grupo o grupos sociales capaces de imponer, dentro de un sistema determinado (el juego de las mayorías parlamentarias en un sistema democrático) su voluntad organi-

102 Palomeque/Álvarez de la Rosa (1996) 43.

103 Palomeque (2002) 32-33.

104 García Ortega, Jesús, et al. (1996) Curso de Derecho del Trabajo. 5a edición. Valencia: Editorial Tirant lo Blanch, 569 pp., p. 29. 
zativa. El conflicto social y la norma jurídica reguladora del mismo formarán parte ya, una vez producida la institucionalización de aquel, de la misma realidad jurídica" 105 .

3.- La función anterior propuesta por la doctrina citada, se puede traducir como modelo legitimador o hegemónico del sistema de producción capitalista, el cual se proyecta en una función pacificadora, y que a su vez se refleja, como es lógico, en la misma normativa del Derecho del Trabajo al establecer límites al desarrollo de las figuras colectivas y organizativas de los trabajadores en el orden de impedir toda perspectiva de superar el actual sistema económico, político y social ${ }^{106}$. Estas reflexiones no son puramente teóricas, por cuanto se pueden perfectamente validar con algunas de las recientes leyes laborales que han entrado en vigencia en nuestro país ${ }^{107}$.

4.- Por otra parte, si analizamos la regulación de las relaciones laborales en Chile nos damos cuenta que ella está dada por la tutela estatal al trabajador a través de normas de orden público que reglamentan el contenido del contrato de trabajo sin que las partes puedan alterar sus disposiciones, salvo para establecer mejores condiciones para el trabajador, siendo la principal fuente reguladora de las relaciones de trabajo la ley, relegando a un segundo plano la autonomía colectiva. La ideología de este sistema respecto del derecho colectivo, recae en el hecho que "el mundo político no mira con buenos ojos el surgimiento de poderes intermedios, de naturaleza sindical. Existe pánico al conflicto, lo que redunda en el excesivo control de las elites políticas en el movimiento sindical". Así, "el sistema reglamentarista es propio de democracias más formales que reales, en naciones más autoritarias que pluralistas, en las que el eventual respeto

105 Palomeque/Álvarez de la Rosa (1996) 44.

106 Esta cuestión es propia del efecto regulador/legitimador del derecho y en particular del derecho del trabajo. Desde un análisis de derecho comparado e histórico, la principal y más notable manifestación de legislación laboral en materia colectiva como expresión de la legalización de la explotación de la fuerza de trabajo y la represión de la acción obrera, se dio en la legislación francesa, particularmente con la ley Le Chapelier de 1791 y sus leyes complementarias como el Código Penal de 1810, quienes como cuerpo normativo, prohibían todas las manifestaciones que hoy calificaríamos como manifestación libertad sindical, declarando inconstitucional los acuerdos entre trabajadores y patrones, al nivel de tipificar conductas constitutivas de expresión de la autonomía colectiva. La efectividad represiva de tal modelo funcionó como normativa de exportación a países industrializados como Gran Bretaña, Dinamarca, España y Alemania.

Desde un punto de vista latinoamericano, la represión de la actividad sindical se hizo efectiva con especial dureza y no precisamente de la ley. Se recuerda a propósito de su brutalidad de hitos de sangre como Santa María de Iquique (1907, Chile); Río Blanco y Cananea (México, 1906-1907); la Patagonia argentina (Argentina, 1921) y los Huelguistas de United Fruits (Colombia, 1928), entre otros.

107 En relación a la función pacificadora, en el mensaje de la ley 20.087 se indica, destacadamente, que la configuración del proceso laboral constituye un instrumento de pacificación social en cuanto dicho proceso se considera un mecanismo privilegiado de solución eficiente y oportuna de conflicto en el ámbito laboral. Historia de la Ley No 20.087, pp. 11 y ss. 
y fomento del sindicalismo va de la mano con la necesaria profundización del sistema democrático"108. Lo anterior justifica realizar un análisis de la realidad nacional en cuanto a la poca influencia de las relaciones colectivas de trabajo como instrumento útil para establecer condiciones de trabajo. Este mecanismo se expresa en el poder conjunto que dispone el empresario y trabajador para fijar el marco regulatorio en que se desenvuelve el conflicto entre el capital y el trabajo. Para la doctrina laboral este mecanismo es conocido como autonomía colectiva ${ }^{109}$.

\section{3) La contribución de la Organización Sindical EN La REGULACIÓN DEL CONFLICTO}

1.- El escenario descrito es particularmente criticable, puesto que la autonomía colectiva como elemento constitutivo de la Libertad Sindical parte de la base del conflicto en las relaciones de trabajo, sin excluir el diálogo y las posibilidades de afinidad entre los actores sociales y sus intereses contrapuestos.

En efecto, "el conflicto entre capital es consustancial a la sociedad industrial y, por ello, a las relaciones laborales. Los conflictos de intereses son inevitables en todas las sociedades. Existen normas para resolverlos, pero no pueden existir normas para eliminarlos" ${ }^{110}$.

En este sentido, en los países desarrollados se impone el modelo de "pluralismo conflictual", que reconoce al conflicto como una característica esencial de la sociedad y la considera como un valor positivo, institucionalizándolo como medio de integración y de progreso del sistema social. Sin embargo, el conflicto puede cumplir esta doble función de estabilización institucional, en base a ciertas condiciones de definición del conflicto a través de criterios razonables ${ }^{11}$. La libertad sindical y su descripción teórica dentro de nuestro marco legislativo, se encuentra homogeneizada con aquellas visiones parcializadas de un modelo económico y descritas con acentos fuertemente formales, alejándose de una estructura-

108 Gamonal Contreras, Sergio (2011) Derecho Colectivo del Trabajo. Santiago: Editorial LegalPublishing, 521 pp., p. 16.

109 Carro Igelmo señala que "las legislaciones positivas lentamente, hubieron de admitir la existencia de otras fuentes jurídicas distintas del Estado para el marco laboral. Y así, se va imponiendo la tendencia a reconocer las facultades normativas de las organizaciones profesionales respecto a sus propios campos de actuación”. El mismo autor clarifica que el convenio colectivo constituye una fuente del Derecho que no existe en las restantes ramas jurídicas "su eficacia emerge del poder normativo ejercido conjuntamente por los sindicatos obreros y las organizaciones empresariales". Carro Igelmo, Alberto (1991) Curso de Derecho del Trabajo. Barcelona: Editorial Bosch, 685 pp., p. 147 y ss.

110 Khan-Freund (1987) 65.

111 Gamonal Contreras (2011) 57. 
ción que favorezca su efectividad como derecho fundamental de finalidad múltiple y de ejercicio autónomo por sus titulares, de manera que no restrinja su alcance a la relación de trabajo, productividad y remuneración.

Esto último, la limitación del Derecho Colectivo, coincide con el panorama general latinoamericano ${ }^{112}$. La minimalización de los movimientos sindicales y la reestructuración económica que conllevó la desmantelación del modelo de relaciones colectivas, trajo consigo la precarización de las condiciones de trabajo lo que influyó considerablemente en el fundamento del sindicato, el cual cambia de una naturaleza clasista a una asistencialista, perdiendo su rol político dentro de la sociedad y relegándose al mantenimiento de empleos y reivindicaciones mínimas para mejorar las condiciones de sus afiliados.

La libertad sindical constituye uno de los ejes centrales de nuestra disciplina, qué duda cabe, implica el reconocimiento del conflicto en las relaciones de trabajo, la importancia del diálogo y la necesidad de afinidad entre los diversos intereses sociales. En efecto, en cualquier sistema de derecho colectivo su conformación recae en el conflicto contrapuesto de las expectativas de empresarios y trabajadores y las soluciones propuestas para resolver tales antinomias. Como lo explica Kahn-Freund, el conflicto se refleja en que "las legítimas expectativas entre trabajadores y empresarios pertenecen a la clase de las que inevitablemente entran en conflicto. Los empresarios pueden legítimamente aspirar a encontrar fuerzas de trabajo a un precio que les permita un margen razonable para la inversión, y los trabajadores del mismo modo, pueden legítimamente aspirar a que su nivel real de salario no permanezca estancado, sino que se incremente progresivamente. Los empresarios pueden expresar su interés legítimo en encontrar el trabajador más adecuado para cada puesto de trabajo; los trabajadores pueden expresar un interés legítimo en obtener un puesto de trabajo para cada trabajador en desempleo" 113 .

2.- La necesidad se enfoca, por tanto, en encuadrar el fenómeno del trabajo en las líneas de relaciones sociales no armónicas y en conflicto permanente derivado de la pertenencia de grupos sociales diferenciados. La conflictividad social que atraviesa todo el derecho del trabajo es especialmente notoria en el derecho sindical acostumbrado a medirse en términos de poder, entendiendo que los sindicatos se hallan objetivamente en una posición dialéctica de contrapoder respecto de los empleadores y

\footnotetext{
112 Al respecto De la Garza Toledo, Enrique (2000) "La Flexibilidad del trabajo en América Latina"; LucenA, Héctor (2000), "El cambio de las relaciones industriales en América Latina", ambos en De la Garza Toledo (Coordinador), Tratado latinoamericano de sociología del trabajo, D.F., Fundación de Cultura Universitaria, pp. 148-178 y 422-450, respectivamente.

113 Kahn-Freund (1987) 112. En similares términos Gamonal Contreras (2011) 56.
} 
que la defensa de sus objetivos no se basa en fórmulas de composición de intereses o de colaboración, sino de autodefensa ${ }^{114}$.

Debemos, al respecto, poner relieve en que el ordenamiento jurídico formal es inadecuado para regular las relaciones entre quienes detentan el poder y quienes carecen de él. Las relaciones de trabajo presuponen una asimetría de poder entre los sujetos que la conforman, en la que trabajadores se subordinan al mandato y obediencia de sus empleadores en función de un orden social determinado. En estos términos, el contrato de trabajo constituye una ficción que oculta y distorsiona una distribución desigual de poder, siendo la única fórmula para superar o igualar su construcción, considerar al Derecho del Trabajo desde el ejercicio de un derecho colectivo, con el objeto de mitigar las asimetrías que supone el Derecho Individual, permitiendo el desarrollo de ciertos niveles de autonomía que posibiliten la generación de sus propias normas. En otros términos las relaciones de trabajo deben entenderse desde el prisma de las relaciones colectivas que surgen de la creación espontánea de un poder social por parte de los trabajadores y como contrapeso al poder normativo y decisorio del capital ${ }^{115}$. No debemos olvidar que "el derecho de las obligaciones postula la autonomía de la voluntad, y el derecho del trabajo organiza la sumisión de la voluntad"116.

3.- Esta forma de entender el Derecho del Trabajo permite atenuar las desigualdades de poder, constituyéndose y configurando su normatividad de manera dinámica en base a la interacción de empresarios y trabajadores (agrupados estos últimos en sindicato), de manera que la regulación estatal sea de mínimos y de protección a la actividad sindical. Esto último solo es posible mediante la generación de un sistema de autonomía, en cierta medida mixto, basado principalmente en el rol que han de jugar los actores sociales con relativa independencia del Estado, desplazando la autonomía a la ley como fuente principal reguladora y potenciando una conformación democrática de las relaciones de trabajo, teniendo como eje vertebrador el ejercicio de libertad sindical y en especial la negociación colectiva. Parafraseando a Romagnoli "Corresponde a la autonomía colectiva (¿y si no a quién?) evitar que el derecho del trabajo se coloque a la cabeza para interiorizar y publicitar la filosofía de la flexibilidad"117.

Esta postura normalmente descartada por quienes propugnan la fortaleza del mercado para crear más y mejores puestos de trabajo, con-

114 Baylos Grau, Antonio (2009) Sindicalismo y Derecho Sindical. Albacete: Editorial Bomarzo, 94 pp., p. 11.

115 Blanch Rivas, Josep, et al. (2003) Teoría de las relaciones laborales. Fundamentos. Barcelona: Editorial UOC, p. 175.

116 Supiot (1996) 19.

117 Romagnoli, Humberto (1992), “Las transformaciones del derecho del trabajo", en Experiencias de flexibilidad normativa. Santiago: Universidad Nacional Andrés Bello, 105 pp., p. 27. 
tribuyendo progresivamente a atenuar la pobreza y desigualdad en que se encuentra una gran masa asalariada. Sin embargo, dado el progreso y desarrollo de los derechos fundamentales ${ }^{118}$, no parece viable que una sociedad democrática y participativa no ofrezca una respuesta más cercana al problema, y en nuestra opinión, ello se logra con un actor conocido en las relaciones laborales, el Sindicato. Lo anterior, porque la organización sindical da una respuesta instrumental pacífica a la búsqueda de un consenso mínimo entre trabajadores y empresarios, generándose a su vez una normativa de alta legitimidad y eficacia, como lo son convenios colectivos, el contrato colectivo y los fallos arbitrales, medios clásicos de regular o expresar la autonomía colectiva, esto es el poder normativo conjunto radicado en los dos actores principales de las relaciones de trabajo. A lo menos el mecanismo está disponible en un modelo de sociedad que debe caracterizarse como Estado Social Democrático de Derecho ${ }^{119}$-vertiente constitucional más reciente del estado democrático de derecho- y es hora de utilizarlo con mayor convicción por los actores sociales.

\section{OBSERVACIONES FinALES}

1.- Creemos que la idea que se tiene del Trabajo es central en la discusión de los modelos regulatorios por los cuales se opta al momento de establecer normas que fijen un marco de funcionamiento en una sociedad. En efecto, la conceptualización del Trabajo ha ido variando en su valoración en el tiempo, cuestión que necesariamente es tomada en cuenta al momento de crear las normas jurídicas que regularán la actuación de los individuos en un momento determinado, particularmente dentro de la

118 Sobre el conflicto de derechos fundamentales en Chile ver: Domínguez Montoya, ÁlvaroMella Cabrera, Patricio (2012) "Conflicto de derechos constitucionales y juicio de tutela laboral en Chile: Estado doctrinal, legal y jurisprudencial", en Revista de Derecho de la Pontificia Universidad Católica de Valparaíso, № 39, pp. 177-219. Para una visión crítica de los derechos fundamentales en la relaciones de trabajo ver Domínguez Montoya, Álvaro (2012) "Análisis crítico al Derecho del Trabajo: entre el paternalismo y la emancipación", en Revista de Estudios IUSNOVUM (Pontificia Universidad Católica de Valparaíso), No 5, pp. 19-59.

119 Se trata de un concepto emanado de la teoría constitucional moderna, y se puede conceptuar como aquel Estado democrático de derecho que realiza los principios de la justicia social, incluyéndose en los textos constitucionales, ciertos derechos justiciables a un mínimo económico existencial, a la protección de la salud, a la protección de la familia y a las garantías de condiciones de trabajo humanas. Debiendo prevenirse que no se desnaturaliza el concepto si los derechos sociales, como la salud, habitación, educación y trabajo son desarrollados por la ley, siempre y cuando se garantice su eficacia y concrete la dignidad humana. Ver HäBerle, Peter (2003) El estado constitucional, instituto de investigaciones jurídicas. D.F.: UNAM, 339 pp., p. 224 y ss. Por otro lado, en el derecho nacional el término Estado Democrático y Social de Derecho, admite dos nociones: 1) la de una Estado de Bienestar y 2) Alude al perfeccionamiento del Estado Liberal de Derecho. Ver Aldunate, Eduardo (2008) Derechos Fundamentales. Santiago: Editorial LegalPublishing, p. 68 y ss. 
interacción entre el capital y el trabajo en la sociedad actual, lo que queda particularmente claro al desentrańar los modelos regulatorios de la actividad laboral en las tesis expuestas en los párrafos anteriores.

Así, aquellos modelos enfocados en el trabajo como un valor central en la sociedad, propenderán a establecer leyes protectoras a favor de los trabajadores y que a su vez permitan el desarrollo de la autonomía en las formas de organización de los mismos. Por su parte, aquellos modelos regulatorios impulsados por ideas que relega a un rol menor al trabajo y que privilegian la función empresarial, propenderán a modelos más flexibles en la regulación del trabajo, que permitan una mayor circulación de capitales, descentralización productiva, libertad de despido y contrataciones laborales atípicas. Finalmente, respecto de aquellas ideas que advierten de la crisis de los modelos de sociedad fundados en el trabajo o que postulan derechamente del fin del trabajo como valor central, conlleva necesariamente a la adopción de modelos de relaciones laborales ya no enfocados en la protección del trabajo, sino más bien en el empleo, particularmente en el tránsito entre el desempleo y la ocupación ${ }^{120}$.

Las anteriores observaciones exigen la adaptación del sistema normativo a las exigencias que impone la existencia de nuevos métodos de producción, lo que se manifiesta particularmente en el replanteamiento de elementos tradicionales del Derecho del Trabajo, hasta la adecuación del modelo colectivo y contractual laboral.

2.- Las reflexiones anteriores respecto del trabajo y sociedad, permiten concluir la influencia decisiva de la ideología y su proyección económica en la modulación del Derecho del Trabajo en general, y en nuestro país en particular. En efecto, se observa que la evolución del diseño jurídico de lo laboral ha sido un reflejo de la tensión existente entre una postura liberal política económica ${ }^{121}$ y otra paternalista de carácter socialdemócrata, en la que la primera opta por un mínimo de restricciones, predominando los derechos políticos o de libertad, respecto de los derechos sociales o de prestación, reconociendo al mercado como el instrumento necesario para la utilización eficiente de los factores productivos; y la segunda, que instala una actitud de sospecha frente al mercado, lo que amerita un fuerte control del mismo, proponiendo con mayor o

120 En este modelo lo que importa es la empleabilidad, esto es que ojalá exista un pleno empleo en un momento determinado, sin importar su calidad y duración e incluso, existiendo desempleo, sus efectos negativos son paleados por un sistema de protección social.

121 Para esta postura, las ideas liberales se conciben como una actitud política e intelectual de sospecha frente a todas las formas de poder público y privado y como una afirmación de la libertad y de la igualdad de las personas. Ruiz Tagle, Pablo (2006) "Una visión democrática y liberal de los derechos fundamentales para la Constitución Chilena del Bicentenario", en Bordalí Salamanca, Andrés (coord.) Justicia Constitucional y Derechos Fundamentales. Santiago: LexisNexis, pp. 69-128, pp. 69-70. 
menos intensidad, la concreción de los derechos sociales o de prestación con objeto de concretar la anhelada igualdad social ${ }^{122}$.

En nuestro país, y dada su evolución histórica, se ha pasado de un modelo regulador de origen estatal muy potente, a otro que postula al mercado como la respuesta eficiente para lograr mayores niveles de empleo y aumento de las remuneraciones. Sin embargo, y actualmente, se ha ido configurando una presión reformista al funcionamiento del mercado, imponiéndole cada vez más controles, originando un Derecho del Trabajo ambivalente, que al recibir las influencias de la sociedad civil, adopta soluciones que provienen tanto del sector estatista como de aquellos que defienden la autonomía en un sentido liberal, originando una reglamentación fuertemente criticada tanto por los trabajadores como por los empresarios; para estos últimos, porque es rígida, y para los primeros, por ser desreguladora y precarizante.

3.- Por otra parte, si bien en nuestro país los actores políticos convergen en que el mercado es quien debe responder a la creación de más y mejores empleos y remuneraciones, se reconoce también la fiscalización y vigilancia del funcionamiento del mercado a través de un sistema de control estatal, sea por organismos administrativos de control centralizados (Inspección del Trabajo) o descentralizados (Superintendencias). La discrepancia surge del grado de esa intervención. En este escenario se han ensayado variadas reformas legislativas desde la vuelta a la democracia en nuestro país (1990 a la fecha) ${ }^{123}$, las cuales siguen siendo objeto de gran debate, lo que naturalmente da origen a un Derecho del Trabajo con un

122 Aunque en una posición que no puede calificarse de estatista, Aguilera, explicando la tesis de Dworkin, señala que este considera "que la igualdad es una virtud fundamental de la democracia. Un gobierno legítimo tiene que tratar a todos sus ciudadanos como iguales, esto es, con igual respeto y consideración. Dworkin distingue dos principios fundamentales y distintos que consideran la igualdad como un ideal político. El primero de ellos exige que el gobierno trate a todos como iguales, es decir, con igual consideración y respeto. El segundo principio demanda que el gobierno trate a todos como iguales en la distribución de ciertos recursos vinculados con las oportunidades, estos han de ser distribuidos, en la medida de lo posible, equitativamente, de manera que la misma porción esté destinada a satisfacer las aspiraciones de cada uno". Aguilera Portales, Pablo (2009) "La función de la filosofía política y jurídica en Ronald Dworkin”. Revista Letras Jurídicas Veracruz, No 20, julio 2009, 105-125 pp., p. 11.

123 GonzÁlez, Cristian (1999), "El derecho laboral en Chile: Situación actual y propuesta de reforma", en Escobar S., Patricio (editor): Trabajadores y Empleo en el Chile de los noventa. Santiago: LOM, pp. 1-229, pp. 83-136; Gamonal Contreras, Sergio (2011) "El futuro del Derecho Laboral: un análisis en perspectiva desde la vuelta de la Democracia" en Trabajo y Derecho. Santiago: LegalPublishing, pp. 1-223., pp. 207-223. 
marcado tinte de provisionalidad, conectado a dos de sus características: su rasgo politizado e ideológico ${ }^{124}$ y su imperfección legislativa ${ }^{125}$.

4.- En el contexto anterior, la visión expuesta respecto del entendimiento del Derecho del Trabajo en la presente investigación permite atenuar las desigualdades de poder que ostenta el dueño del capital respecto del asalariado, generándose una normatividad de manera dinámica en base a la interacción de empresarios y trabajadores como sujetos de una realidad conflictiva -estos últimos agrupados necesariamente en sindicatos-, de manera que la regulación estatal sea de mínimos y de protección a la actividad sindical. Esto último solo es posible con la generación de un sistema de autonomía, en cierta medida mixto, basado principalmente en el rol que han de jugar los actores sociales con relativa independencia del Estado, desplazando la prevalencia de la ley como fuente principal reguladora y potenciando una conformación democrática de las relaciones de trabajo que tenga como eje vertebrador el ejercicio de libertad sindical, en especial la negociación colectiva y la huelga, proscribiendo progresivamente el paternalismo estatal ${ }^{126}$, ya que "la legislación es generalmente más rígida que la negociación colectiva y obviamente se adapta muchos menos a los cambios económicos"127.

Ahora bien, ello no descarta la aplicación de las otras fuentes usuales que el Derecho del Trabajo utiliza para resolver los problemas o controversias que surgen en las relaciones individuales y colectivas de trabajo; pero dan cuenta de la necesidad de sustituir una fuente clásica (la ley), por otra disponible y que entregaría un servicio más eficiente al conflicto (autonomía colectiva).

5.- Reiteramos, como método necesario para superar los efectos negativos de una lectura liberal del Derecho del Trabajo que se debe asumir que a través de la ley se cumple una función pacificadora, protectora y

124 "El derecho del trabajo posee, por otra parte, como característica la de estar más alejado de la técnica jurídica que otras ramas del derecho, y más próximo a las luchas ideológicas" (...) "No es posible enumerar las corrientes ideológicas que se enfrentan, luchan o se alían: individualismo liberal, hoy bastante en desuso; capitalismo "popular" o neocapitalismo, que repudia el corporativismo o el paternalismo de antaño, pero busca la colaboración del capital y del trabajo; tendencia tecnocrática, cuyo único valor es la eficacia y que se desarrolla sobre todo en el sector público; cristianismo social, cuya doctrina, elaborada por las grandes encíclicas papales (Rerum novarum, Cuadragésimo anno) ha sido puesta al día por la encíclica Mater et magistra del papa Juan XXIII, hostil tanto liberalismo como a la lucha de clases, y que propugna la justicia social; reformismo; marxismo, diversamente interpretado: tantas doctrinas como posiciones adoptadas sobre los problemas esenciales.” Camerlynk, G.H.; Lyon- Caen, G., (1974), 39, 40; Javillier (1982) 112-119; Palomeque (2002).

125 Gamonal Contreras, Sergio (1998) Introducción al Derecho del Trabajo. Santiago: Jurídica ConoSur, 231 pp., p. 106.

126 En esta línea se ha dicho "empresarios y sindicato, al constituir fuerzas contrapuestas y equilibradas, son capaces de crear mediante su actuación autónoma un cuerpo de normas, relevando así a las leyes de una de sus funciones”. KaHn-Freund (1987) 116. Ibíd. 103. 
conciliadora, que muchas veces oculta las contradicciones entre el capital y el trabajo, impidiendo el desarrollo de figuras colectivas de organización de trabajadores. A nuestro criterio, una forma de cambiar esta visión actual del Derecho del Trabajo es aquella que encuadra en líneas de relaciones sociales no armónicas, en conflicto permanente derivado de la pertenencia de grupos sociales diferenciados, entendiendo que los sindicatos se hallan objetivamente en una posición dialéctica de contrapoder respecto de los empleadores y que la defensa de sus objetivos no se basa en fórmulas de composición de intereses o de colaboración, sino de autodefensa.

Por lo demás la existencia de sindicatos dentro de una sociedad democrática sin ninguna duda contribuye al funcionamiento exitoso de un sistema social más inclusivo por cuanto se produce una participación de un gran colectivo de ciudadanos, que al acordar ciertas condiciones de trabajo con sus empleadores fijan las bases de una "paz social” en una época determinada.

De esta forma, y dado el actual escenario en nuestro país que enfrenta una gran demanda social, se hace necesario proponer un marco regulatorio del Derecho del Trabajo, que destierre un derecho de retórica, introduciendo, aunque gradualmente, una normativa contrahegemónica y emancipadora a fin de obtener una regulación eficaz y justa que dé una respuesta oportuna al conflicto entre el capital y el trabajo, logrando de esta manera un desarrollo económico y social más equitativo.

\section{BIBLIOGRAFÍA}

- Aguilera Portales, Pablo (2009) "La función de la filosofía política y jurídica en Ronald Dworkin". Revista Letras Jurídicas Veracruz, No 20, julio 2009, pp. 105-125.

- Aguillo, Tomás (1998) "La centralidad del trabajo en el proceso de construcción de la identidad de los jóvenes". Revista Psicothema, vol. 10, No 1, pp. 153-165.

- Aldunate, Eduardo (2008) Derechos Fundamentales. Santiago: Ed. LegalPublishing.

- Amauri Mascaro, Nascimento (1999) Teoría General del Derecho del Trabajo. São Paulo, LTR.

- Amézquita Quintana, Constanza, (2009) "Alienación y Emancipación. Una reflexión teórica sobre estos dos conceptos”. Revista de Ciencias Sociales Comunicación, Cultura y Politica, No 1, vol. 2, pp. 45-54.

- Atienza, Manuel y Ruiz Manero, Juan (2004) Marxismo y Filosofía del Derecho. D.F: Editorial Fontamara.

- Balandier, Georges (1993) El desorden. La teoría del caos en las ciencias sociales. DF.: Editorial Gedisa. 
- Barbagelata, Héctor-Hugo (2009) Curso sobre la evolución del pensamiento Juslaboralista. Montevideo: FCU.

- Baylos Grau, Antonio (2009) Sindicalismo y Derecho Sindical. Albacete: Editorial Bomarzo.

- Baylos, Antonio (1991) Derecho del Trabajo: modelo para armar. Madrid: Editorial Trotta.

- Bencomo, Tania (2008) "El trabajo visto desde una perspectiva social y jurídica". Revista Latinoamericana de Derecho Social, No 7 , julio-diciembre, pp. 27-57.

- Blanch Rivas, Josep, et al. (2003) Teoría de las relaciones laborales. Fundamentos. Barcelona: Editorial UOC.

- Bobвio, Noberto (2001) Marx y la teoría del Derecho. DF: Fondo de Cultura Económica.

- Boвbio, Norberto, (2001) Ni con Marx ni contra Marx. D.F: Editorial FCE.

- Borrajo Dacruz, Efrén (1989) Introducción al Derecho del Trabajo, 6a Ed. Madrid: Editorial TECNOS.

- Boyer, Robert (1986) "La flexibilidad del trabajo en Europa". Madrid: Centro de publicaciones ministerio del trabajo y seguridad laboral.

- Caamaño Rojo, Eduardo (2008) "Las materias objeto de negociación colectiva y la libertad sindical: el fantasma de los "Chicago Boys" a 30 años del plan laboral", en Estudios Laborales, No 3 año 2008.

- Cabanellas de Torres, Guillermo (1987) Compendio de Derecho Laboral. Tomo I, vol. 13a ed. Buenos Aires: Editorail Helisiasta.

- Camerlynk, G.H.; Lyon- Caen, G. (1974) Derecho del Trabajo. Madrid: Ed. Aguilar.

- Cárdenas Rivera, Miguel (2004) Justicia pensional y neoliberalismo: Un estudio de caso sobre la relación. Bogotá: Editorial ILSA.

- Carro Igelmo, Alberto (1991) Curso de Derecho del Trabajo. Barcelona: Editorial Bosch.

- Castel, Robert (1997) La metamorfosis de la cuestión social. Buenos Aires: Editorial Paidós.

- Cerroni, Umberto (1965) Marx y el Derecho Moderno. Buenos Aires: Editorial Jorge Álvarez Editor.

- Correas, Óscar (1998) Sociología del Derecho y crítica jurídica. D.F: Editorial Fontamara.

- Correas, Óscar (2005) Crítica de la ideología jurídica. D.F.: UNAM.

- Coser, Lewis (1970) Nuevos Aportes a la Teoría del Conflicto Social. Buenos Aires: Amarrortur.

- Dávalos Morales, José (1997) "Conflictos del Trabajo", en Instituciones de Derecho del Trabajo, Academia Iberoamericana de 
Derecho del Trabajo y de la Seguridad Social. D.F.: UNAM, pp. 215250.

- De la Garza Toledo, Enrique (2000) "La Flexibilidad del trabajo en América Latina" en De la Garza Toledo (coordinador): Tratado latinoamericano de sociología del trabajo. D.F.: Fundación de Cultura Universitaria, pp. 148-178.

- De La Garza, Enrique (1999) “¡Fin del trabajo o trabajo sin fin?", en Castillo, Juan José (editor): El trabajo del futuro. Madrid: Complutense.

- Domínguez Montoya, Álvaro; Mella Cabrera, Patricio (2012) "Conflicto de derechos constitucionales y juicio de tutela laboral en Chile: Estado doctrinal, legal y jurisprudencial”. Revista de Derecho de la Pontificia Universidad Católica de Valparaíso, $\mathrm{N}^{\circ} 39$.

- Domínguez Montoya, Álvaro (2012) "Análisis crítico al Derecho del Trabajo: entre el paternalismo y la emancipación”. Revista de Estudios IUSNOVUM (Pontificia Universidad Católica de Valparaíso), No 5.

- Ermida Uriarte, Óscar (2006) "Ética y Derecho del Trabajo". Iuslabor, No 1, Universitat Pompeu Fabra.

- Ermida Uriarte, Óscar, Meditación sobre el derecho del trabajo. Cuadernillos de la fundación Electra.

- Ermida Uriarte, Óscar (2001) "Protección, igualdad, dignidad, libertad y no discriminación DL no 241". Derecho Laboral, No 241 vol. 54, (ene/mar 2011), pp. 7-23.

- Ermida Uriarte, Óscar; Hernández Álvarez, Óscar (2003) "Critica de la subordinación". Estudios jurídicos en homenaje al doctor Néstor de Buen Lozano. D.F.: UNAM, pp. 269-297.

- Ermida, Óscar (2001) La flexibilidad. Montevideo: Fundación de Cultura Universitaria.

- Forrester, Vivian (1997) El horro económico. Buenos Aires: Fondo de Cultura Económica.

- Foucault, Michel (1996) Genealogía del racismo. Cantabria: Altamira Press.

- Foucault, Michel (1996) La Verdad y las Formas Jurídicas, 2a ed. Corregida. Traducción de Enrique Lynch. Barcelona: Ed. Gedisa.

- Foucault, Michel (1999) "Las mallas del poder". Estética, ética y hermenéutica. Obras esenciales. Vol. III. Barcelona: Paidós.

- Foucault, Michel (1999) "La Ética del Cuidado de sí como práctica de la Libertad". Obras Esenciales Estética, Ética y Hermenéutica, volumen III. Traducción de A. Gabilondo. Barcelona: Paidós.

- Foucault, Michel (2004) "Poderes y Estrategias". Un diálogo sobre el poder y otras conversaciones, $1^{\text {a }}$ reimp. Madrid: Alianza Editorial.

- Foucault, Michel (2006) Defender la Sociedad. Curso en el Collège de France (1975-1976), 2a ed. Traducción de H. Pons. D.F.: FCE. 
- Foucault, Michel (2008) Historia de la Sexualidad. Vol. 1. La Voluntad de Saber, 2a ed. Traducción de U. Guiñazú. Buenos Aires: Siglo XXI.

- Foucault, Michel (2008) Nietzsche, la Genealogía, la Historia, 6a ed. Traducción de J. Vásquez Pérez. Valencia: Pre-textos.

- Fromm, Erich (1962) Marx y su Concepto del Hombre. D.F: Editorial Fondo de Cultura Económica, 272 pp.

- Fromm, Erich (1986) Anatomía de la destructividad humana. D.F.: Editorial S. XXI.

- Gamonal Contreras, Sergio (1998) Introducción al Derecho del Trabajo. Santiago: Jurídica ConoSur.

- Gamonal Contreras, Sergio (2004) Ciudadanía en la Empresa. Montevideo: FCU.

- Gamonal Contreras, Sergio (2005) Daño moral en el contrato de trabajo. Santiago: LexisNexis.

- Gamonal, Sergio (2008) Fundamentos de Derecho Laboral. Santiago: Editorial LexisNexis.

- Gamonal Contreras, Sergio (2011) "El futuro del Derecho Laboral: un análisis en perspectiva desde la vuelta de la Democracia" en Trabajo y Derecho. Santiago: LegalPublishing.

- Gamonal Contreras, Sergio (2011) Derecho Colectivo del Trabajo. Santiago: Editorial LegalPublishing.

- Gamonal Contreras, Sergio (2011) "Flexiseguridad: mitos y desafíos" en Trabajo y Derecho. Santiago: LegalPublishing.

- García Ortega, Jesús, et al. (1996) Curso de Derecho del Trabajo. $5^{a}$ edición. Valencia: Editorial Tirant lo Blanch.

- García Villegas, Mauricio; Uprimmy, Rodrigo (2004) "Corte Constitucional y Emancipación Social en Colombia", en De Sousa Santos, Boaventura y García Villegas, Mauricio (editores): Emancipación Social y Violencia en Colombia. Bogotá: Editorial Norma.

- Godio, Julio (2011) Sociología del trabajo y política. Buenos Aires: Editorial Corregidor.

- GonzÁlez, Cristian (1999) "El derecho laboral en Chile: Situación actual y propuesta de reforma". En Escobar S., Patricio (editor): Trabajadores y Empleo en el Chile de los noventa. Santiago: LOM.

- Gorelli Hernández, Juan (2013) "Crítica a la flexiseguridad". Revista Latinoamericana de Derecho Social, No 16, enero-junio, pp. 51-82.

- Gorz, André (1998) Miserias del presente, riqueza de lo posible. Buenos Aires: Editorial Paidós.

- Guastini, Ricardo (1982) "La ambigua utopía. Marx criticato da Kelsen". Revista Sociología del diritto, 2. 
- Guastini, Ricardo (1989) "Kelsen y Marx", en Correa, Óscar (coordinador): El otro Kelsen. D.F.L.: Universidad Nacional Autónoma de México, pp. 79-98.

- Häberle, Peter (2003) El estado constitucional, instituto de investigaciones jurídicas. D.F.: UNAM.

- Habermas, Jürgen (1987) Teoría de la acción comunicativa, vol. I. Madrid: Editorial Taurus.

- Habermas, Jürgen (1988) "La crisis del Estado de bienestar y el agotamiento de las energías utópicas". Ensayos políticos. Barcelona: Península.

- Habermas, Jürgen (1989) El discurso filosófico de la modernidad. Madrid: Editorial Taurus.

- HAYeK, Friedrich (1982). "Los principios de un orden social liberal". Estudios Públicos, No 6, Centro de Estudios Públicos.

- Hayer, Friedrich (1986) "El paro y los sindicatos en los ańos ochenta". En Huerta de Soto, Jesús (coordinador): Lecturas de Economía Política, Vol. 2. Madrid: Unión Editorial.

- HayeK, Friedrich (2008) Los fundamentos de la Libertad, 8a Edición. Madrid: Unión Editorial S.A.

- Hayek, Friedrich (2008) Nuevos Estudios de Filosofía, Política, Economía e Historia de las Ideas. Madrid: Unión Editorial.

- Huerta de Soto, Jesús (2001) Socialismo, Cálculo Económico y Función Empresarial. Madrid: Unión Editorial.

- Huerta de Soto, Jesús (2001) Nuevos Estudios de Economía Politica. Madrid: Unión Editorial.

- Huerta de Soto, Jesús (2004) Estudios de Económica Política, 2a edición. Madrid: Unión Editorial.

- Irureta Uriarte, Pedro (2009) "Regulación de la Libertad Sindical entre 1973-1990". En Lira, Elizabeth y Rojas, Hugo (editores): Libertad Sindical y Derechos Humanos. Análisis de los Informes del Comité de Libertad Sindical de la OIT (1973-1990), 1a Edición. Santiago: Editorial LOM.

- Jaques, Elliott (1968) Trabajo, incentivos y redistribución. Buenos Aires: Editorial Hormé S.A.E., Paidós.

- Javillier, Jean-Claude (1982) Derecho del Trabajo. Madrid: Ed. Instituto de Estudios Laborales y Seguridad Social.

- Jeammaud, Antoine (1986) "La Crítica del Derecho en Francia: De la búsqueda de una teoría materialista del derecho al estudio critico de la regulación jurídica" en Miaille, Michel et al.

- Kelsen, Hans (2005) Teoría pura del derecho. Traducción de R. Vernengo. Buenos Aires: Editorial Porrúa.

- Kahn-Freund, Otto (1987) Trabajo y Derecho, $3^{a}$ edición. Traducción de Jesús M. Galiana Moreno. Madrid: Ministerio de Trabajo y Seguridad Social. 
- Lagos Matus, Gustavo (1950) El problema histórico del Trabajo. Santiago: Editorial Jurídica.

- Lucena, Héctor (2000) "El cambio de las relaciones industriales en América Latina”. En De la Garza Toledo (coordinador): Tratado latinoamericano de sociología del trabajo. D.F.: Fundación de Cultura Universitaria.

- Martínez Rivera, Ramón (2012) Estudios de economía y legislación laboral. Memoria de prueba para optar al grado de Licenciado en Ciencias Jurídicas y Sociales, Facultad de Derecho, Universidad de Chile.

- Martínez Vivot, Julio (1994) Elementos de Derecho de Trabajo y de la Seguridad Social, 2a Ed., Buenos Aires: Editorial Astrea.

- Marx, Karl (1884) Manuscritos económico-filosóficos de 1844. Apéndice en Fromm, Erich (1962).

- Marx, Karl (1966) El Capital: Crítica de la Economía Politica, Tomo I. DF: FCU, 953 pp.

- Marx, Karl (1999) Capital, Trabajo, Plusvalía: Conceptos Básicos. Buenos Aires: Errepal.

- McNeil, B. Elton (1975) La naturaleza del conflicto humano. D.F.: Editorial FCE.

- MÉda, Dominique (1998) El trabajo. Un valor en peligro de extinción. Traducción de Marc Valls. Barcelona: Ed. Gedisa, Col. Hombre y Sociedad.

- Melis Valencia, Christian (2010) Los derechos fundamentales de los trabajadores como limites a los poderes empresariales. Santiago: LegalPublishing.

- Menger, Carl (1985) Principios de economía politica. Madrid: Unión Editorial.

- Miaille, Michel; Jeammaud, Antoine et al. (2008) La Crítica Jurídica en Francia. Puebla: Universidad Autónoma de Puebla.

- Mises, Ludwig (1986) La acción humana. Tratado de Economía, 4a Edición. Madrid: Unión Editorial.

- Montoya Melgar, Alfredo (1995) Derecho del Trabajo, 16ª. Ed. Madrid: Editorial TECNOS.

- Neffa, Julio César (2001) "Presentación del debate reciente sobre el fin del trabajo". En Neffa, Julio César y De la Garza Toledo, Enrique (compiladores): El trabajo del futuro. El futuro del trabajo. Buenos Aires: CLACSO.

- Noguera, José Antonio (1998) La transformación del concepto de trabajo en la teoría social: La aportación de las tradiciones marxistas, tesis doctoral. Barcelona: Universidad Autónoma de Barcelona.

- Noguera, José Antonio (2000). "El problema de la definición del trabajo", Ponencia presentada en los I Encuentros entre Humanidades y Ciencias Sociales, Institut Universitari de Cultura, 
Universitat Pompeu Fabra, Inédito, fecha 18-20 de enero de 2000, Barcelona: inédita.

- Noguera, José Antonio (2002). "El concepto de trabajo y la teoría social crítica". Revista de Sociología Universidad Autónoma de Barcelona, Papers No 68, pp. 141-168.

- Offe, Claus (1992) La sociedad del trabajo. Problemas estructurales y perspectivas del futuro. Madrid: Editorial Alianza Universidad.

- Palomeque, Manuel (2002) Derecho del Trabajo e ideología. Madrid: Editorial TECNOS.

- Panzieri, Rainero, et al. (1989) La división capitalista del trabajo. Córdoba: Cuadernos de Pasado y Presente.

- Pérez González, José; Díaz Vilela, Luis (2005) La centralidad del trabajo. USA: LULU.

- Pérez Lledó, Juan (2005) “Teorías críticas del Derecho". En Garzón Valdés, Ernesto y Laporta, Francisco (editores): El derecho y la justicia. Editorial Trotta.

- Pérez Llego, Juan (1993) El Movimiento Critical Legal Studies, tesis doctoral. Alicante: Universidad de Alicante, Facultad de Derecho.

- Pla Rodríguez, Américo (1975) Los principios del Derecho del Trabajo. Montevideo: Depalma, pp. 1-333;

- Poulantzas, Nicos, et al. (1970) Hacia una teoría marxista. Cali: Nueva Era, 90 pp.

- Rochabrún, Guillermo (2007) Batallas por la Teoría, en torno a Marx y el Perú. Lima: Editorial IEP.

- Rojas Miño, Irene (2007) "Las reformas laborales al modelo normativo de negociación colectiva del plan laboral". Revista Ius et Praxis, Vol. 13, No 2, 2007, pp. 195-221.

- Romagnoli, Humberto (1992) "Las transformaciones del derecho del trabajo". Experiencias de flexibilidad normativa. Santiago: Universidad Nacional Andrés Bello.

- Romagnoli, Umberto (1997) El Derecho, el Trabajo y la historia. Madrid: Consejo Económico y Social.

- Rifkin, Jeremy (2014) El fin del Trabajo. Barcelona: Paidós.

- Ruiz Manero, Juan (1986) Sobre la crítica de Kelsen al marxismo. Doxa 03, pp. 191-231.

- Ruiz Tagle, Pablo (2006) "Una visión democrática y liberal de los derechos fundamentales para la Constitución Chilena del Bicentenario". En Bordalí Salamanca, Andrés (coordinador): Justicia Constitucional y Derechos Fundamentales. Santiago: LexisNexis.

- Sanchis, Enric (2011) Trabajo y paro en la sociedad postindustrial. Valencia: Editorial Tirant lo Blanch.

- Simmel, George (2010) El conflicto. Sociología del antagonismo. Traducción de Javier Eraso Ceballos. Madrid: Edit. Sequitu. 
- Smith, Adam (1988) La riqueza de las naciones. Vol I. Barcelona: Oikos-tau.

- Somavía, Juan (1999) Trabajo decente. Memoria del Director General, $87^{a}$ Conferencia Internacional del Trabajo. OIT: Ginebra.

- Supiot, Alain (1996) Crítica del Derecho del Trabajo. Madrid: Ministerio del Trabajo y Asuntos Sociales, 312 pp.

- Thayer Arteaga, William; Novoa Fuenzalida, Patricio (1980) Manual de Derecho del Trabajo. Santiago: Editorial Jurídica de Chile.

- Ugarte Cataldo, José Luis (2004) Derecho del Trabajo, flexibilidad laboral y análisis económico del derecho. Santiago: LexisNexis.

- Ugarte Cataldo, José Luis (2007) El nuevo Derecho del Trabajo. Santiago: Editorial LexisNexis.

- Ugarte Cataldo, José Luis (2011) "Los derechos fundamentales del trabajador y la buena fe en el debate español". Revista de Derecho de la Pontificia Universidad Católica de Valparaíso, No 36, $1^{\text {er }}$ Semestre, pp. 141-164.

- Valqui Cachi, Camilo; Pastor Bazán, Cutberto (Coordinadores), (2009) "Corrientes Filosóficas del Derecho: una crítica antisistémica para el siglo XXI". Cajamarca: Facultad de Derecho y Ciencia Política, Universidad de Cajamarca.

- Valverde, Martín et al., Derecho del Trabajo (4a ed.). Madrid: Tecnos.

- Wolkmer, Antonio Carlos (2006) Introducción al pensamiento jurídico crítico. D.F: ILSA/UASLP/CEDH.

- Wood, Allen (1989) "Marx y la igualdad". En Roemer, John E. (compilador): El marxismo una perspectiva analitica. D.F.: Fondo de Cultura Económica. 